\title{
Identifying Potential Novel Pathways and Therapeutic Targets of Major Depressive Disorder with Functional Genomics
}

Kevin Bao ( $\square$ kevinbao54@gmail.com )

BioScience Project

\section{Research Article}

Keywords: depression, major depression, major depressive disorder, ketamine, neuroplasticity, neuroinflammation, glutamate, acetylcholine, protein interaction network

Posted Date: March 31st, 2021

DOl: https://doi.org/10.21203/rs.3.rs-374465/v1

License: (ㅇ (i) This work is licensed under a Creative Commons Attribution 4.0 International License.

Read Full License 


\title{
Identifying Potential Novel Pathways and Therapeutic Targets of Major Depressive Disorder with Functional Genomics
}

\author{
Kevin $\mathrm{Bao}^{1}$ \\ ${ }^{1}$ BioScience Project, Wakefield, MA, 01880, USA
}

\begin{abstract}
$\underline{\text { Abstract }}$
Background: Major depressive disorder (MDD) is a debilitating illness and a leading cause of disability, but its pathophysiology remains to be completely elucidated. Resistance to traditional antidepressant treatment is highly prevalent within patient populations. Ketamine, a rapid-acting antidepressant that has shown success in treating resistant patients, is hypothesized to function by modulating excitatory and inhibitory neurotransmitters. This has led to a paradigm shift from the monoaminergic hypothesis, towards a glutamate and neuroplasticity hypothesis, though this picture may still be incomplete. The purpose of this study is to identify novel systems potentially implicated in MDD and suggest potential therapeutic mechanisms.
\end{abstract}

Methods: An integrative genomics and systems biology approach was used to identify genes and pathways that may be relevant to MDD. Starting with genes implicated in current, wellestablished paradigms, a correlation analysis was used to query publicly available microarray datasets to identify potential genes that may be relevant to MDD. Systems and pathways of interest were identified through functional enrichment. Through a manual review, genes of systems and pathways potentially relevant to MDD were used to generate a protein interaction network. Interesting genes identified from the network were functionally enriched and clustered to identify new high-level themes. Genes from the protein interaction network were then classified into sets based on different paradigms using functional annotations. Genes belonging to multiple sets - and thus being involved in multiple different paradigms relevant to MDD were identified for future research.

Results: The highest-ranked enrichment cluster contained GABAeric signaling, retrograde endocannabinoid signaling, and morphine addiction. Other interesting pathways identified were $\mathrm{T}$ cell receptor signaling, cocaine addiction, and nicotine addiction. Other broad themes identified in other clusters were calcium, serotonin, the immune system, TGF beta, glutamate, telomeres, the guanine nucleotide exchange factor, the extracellular matrix, and DNA regulation. Potential genes of interest are listed in Table 3.

Conclusions: Throughout the study, interesting genes, groups of genes, and systems were identified manually and systematically, some of which validate existing literature and some give possible directions for future research. Further experiments are required to confirm causal links. 


\section{$\underline{\text { Introduction }}$}

Major depressive disorder (MDD) is a leading cause of disability worldwide, affecting over 264 million people [1] and $7.1 \%$ of adults in the United States [2]. Despite its prevalence, the pathophysiology of depression is still not well understood. The first major paradigm was the monoamine hypothesis, which proposed that lower levels of monoaminergic neurotransmitters serotonin, dopamine, and norepinephrine - contribute to the pathogenesis of MDD. Traditional antidepressants, which include tricyclics, selective serotonin reuptake inhibitors (SSRIs), serotonin-norepinephrine reuptake inhibitors (SNRIs), and monoamine oxidase inhibitors (MAOIs), generally function to increase levels of these neurotransmitters.

Confirming the role of serotonin, the kynurenine pathway (KP) and its metabolites have also been a major interest of current research. The pathway metabolizes tryptophan, the precursor to serotonin, and produces quinolinic acid, an NMDA agonist that can induce excitotoxicity [3]. It is theorized that depressed patients have increased KP activity, resulting in less available tryptophan for serotonin synthesis, and consistent with this, a meta-analysis shows that depressed patients consistently have less tryptophan and kynurenic acid and higher levels of quinolinic acid than controls [4]. Naturally, this leads to questions about the upstream causes and downstream effects of KP dysregulation.

One potential upstream cause is the excess release of glucocorticoids. Tryptophan 2,3dioxygenase controls the rate-limiting step of the KP and is induced by glucocorticoids [5]. Consistent with the psychopathogenesis of depression as a result of chronic stress, glucocorticoids are one of the major hormones released during the stress response. Another enzyme that controls the rate-limiting step of the KP is indoleamine-2,3-dioxygenase, which is induced by inflammatory factors $[6,7]$.

The downstream effects of the KP point towards a role of the NMDA receptor in the biology of MDD, and more broadly neuroplasticity. One of the biggest shortcomings of the monoamine hypothesis is the long delay before traditional antidepressants produce therapeutic effects. Treatment-resistance to traditional antidepressants is also highly prevalent, suggesting that the monoaminergic hypothesis is incomplete. With the discovery of ketamine as an efficacious, rapid-acting antidepressant [8], the predominant paradigm in the current field of depression research has shifted towards a neuroplasticity hypothesis [9] and investigating the roles of glutamate and GABA. Ketamine's mechanism of action is an ongoing area of research, but broadly it increases neuroplasticity by acting as an NMDAR antagonist - protecting against neurotoxicity - and inducing local synaptic protein synthesis [10]. However, this picture may not be entirely complete. Other NMDA antagonists have failed to produce antidepressant effects to the same extent as ketamine [108], which suggests that there are mechanisms unique to ketamine beyond modulation of glutamatergic and GABAergic systems. 
The purpose of this study is to identify novel systems potentially implicated in the pathophysiology of depression as areas of future research and to propose possible therapeutic mechanisms based on molecular function.

\section{Methodology}

The following genes were chosen as representatives from the major current paradigms as a starting point:

SLC6A4, serotonin hypothesis - The serotonin transporter that mediates reuptake of serotonin from the synapse back into the presynaptic neuron. SSRIs inhibit this transporter to increase available synaptic serotonin levels.

HTR1A, serotonin hypothesis - Serotonin autoreceptor that is a part of negative feedback regulation of serotonin, preventing the release of serotonin in the presence of excess synaptic serotonin. Decreased HTR1A activity, through downregulation or desensitization, is associated with antidepressant effects [11].

TDO2, serotonin hypothesis - Tryptophan 2,3-dioxygenase, one of the enzymes of the ratelimiting step of the kynurenine pathway.

BDNF, neuroplasticity hypothesis - Brain-derived neurotropic factor, plays a major role in neuroplasticity and the formation of new synapses.

GRIN2B, glutamate hypothesis - Subunit for the NMDA receptor. This subunit in particular has been implicated in depression [12].

PTGS2, inflammation hypothesis - COX2, a major component of the inflammatory response and a target of NSAIDs. Celecoxib, a selective COX2 inhibitor and NSAID, may have antidepressant effects [13].

CRHR1 \& CRHR2, HPA axis - CRH receptors that play an important role in mediating the stress response.

NR3C1, HPA axis - Glucocorticoid receptor that mediates transcription and downstream effects of glucocorticoids.

The Allen Human Brain Atlas [109] was used to find genesets correlating with the starting genes. The correlate and starting genes were enriched with DAVID $6.8[110,111]$ for KEGG pathways [112]. Manually, interesting pathways were identified from the literature, and the genes in these pathways along with the starting genes comprised the list of candidate genes for subsequent analysis. Candidate genes were visualized in networks with a variety of methods to determine connectivity and structure. STRING 11.0 [113] was used to create a protein-protein interaction (PPI) network that was further analyzed using Cytoscape 3.8.0 [114] and organized and filtered using MCODE 1.6.1 [115] and clusterMaker 1.3.1 [116]. EnrichmentMap 3.3.0 [117] was used 
to construct a pathway interaction network with enriched pathways, and NetworkAnalyst 3.0 [118] was used to create a drug-protein interaction network with the candidate genes.

The candidate gene PPI networks were used to identify further interesting genes to add to the candidate gene list. This new candidate gene list was enriched again with DAVID to identify gene clusters.

Enrichment annotations were then used to group genes from a filtered PPI network into sets based on their involvement in different broad theories of depression: monoamine, neuroplasticity, immune system, neurotrophin, behavioral responses, glucocorticoid, DNA, cholinergic, and endocrine. UpSetR [119] was used to identify intersections between these gene sets.

\section{$\underline{\text { Results }}$}

\section{Identifying Potential Candidate Genes and Pathways}

The Allen Human Brain Atlas was used to find genes that are expressed in correlation to the starting genes. Correlate genes with Pearson correlation coefficient $\geq .65$ from all 9 genes were compiled into a gene list. Running the gene set through DAVID, the genes in the GAD disease class for depression from the set were identified and listed in Table 1. DAVID was also used to identify KEGG pathways enriched in the gene list, which are listed in Table 2. 


\begin{tabular}{|c|}
\hline disrupted in schizophrenia 1 (DISC1). \\
\hline prostaglandin-endoperoxide synthase 2(PTGS2). \\
\hline glutamate metabotropic receptor 7(GRM7). \\
\hline neurotrophic receptor tyrosine kinase 2(NTRK2). \\
\hline cholinergic receptor muscarinic 2 ( \\
\hline CD3e molecule $(\mathrm{CD} 3 \mathrm{E})$. \\
\hline cadherin $13(\underline{\mathrm{CDH} 13})$. \\
\hline phospholipase A2 group IVA(PLA2G4A). \\
\hline glutamate ionotropic receptor AMPA type subunit 3 (GRIA3). \\
\hline corticotropin releasing hormone receptor 1 (CRHR1). \\
\hline aralkylamine $\mathrm{N}$-acetyltransferase(AANAT). \\
\hline brain derived neurotrophic factor(BDNF). \\
\hline potassium two pore domain channel subfamily $\mathrm{K}$ member 2 (KCNK2). \\
\hline myelin transcription factor 1 like(MYT1L). \\
\hline lymphotoxin alpha( \\
\hline empty_spiracles homeobox 2(EMX2). \\
\hline neuronal PAS domain protein 2 (NPAS2). \\
\hline CREB binding_protein(CREBBP). \\
\hline 5-hydroxytryptamine receptor $2 \mathrm{~A}(\mathrm{HTR2A})$. \\
\hline Wnt family member 7A(WNT7A). \\
\hline aryl hydrocarbon receptor nuclear translocator like 2(ARNTL2). \\
\hline neuropeptide $\mathrm{Y}(\mathrm{NPY})$. \\
\hline
\end{tabular}

Table 1

\begin{tabular}{|c|c|c|c|c|c|c|c|c|c|}
\hline Term & Count & PValue & Genes & $\begin{array}{l}\text { Pop } \\
\text { Hits }\end{array}$ & $\begin{array}{l}\text { Pop } \\
\text { Total }\end{array}$ & \begin{tabular}{|l|l} 
Fold \\
Enrichment
\end{tabular} & Bonferroni & Benjamini & FDR \\
\hline $\begin{array}{l}\text { hsa04080:-Neuroactive ligand-receptor } \\
\text { interaction }\end{array}$ & 48 & $8.16 \mathrm{E}-12$ & 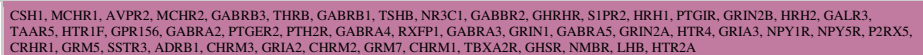 & 277 & 6879 & 3.010 & 2.007E-09 & 2.007E-09 & $1.057 \mathrm{E}-08$ \\
\hline hsa04921:Oxylocin signaling pathway & 28 & $8.07 \mathrm{E}-08$ & $\begin{array}{l}\text { MEF2C, ADCY2, PTGS2, PPP3R1, CACNB1, KCNI12, KCN13, PPP3CB, PLCB1, CAMK2A, PRKCA, CACNA2D1, CAMK1G, GNAO1, ROCK1, CACNG8, } \\
\text { PRKAB2, PRKCG, CACNG3, CACNA2D3, PRKCB, KCNJ4, MAPK1, PLA2G4A, KCNJ6, CAMK1, CALM3, GUCY1B3 }\end{array}$ & 150 & 6879 & 3.243 & $1.985 \mathrm{E}-05$ & $9.923 \mathrm{E}-06$ & $1.045 \mathrm{E}-04$ \\
\hline hsa04724:Glutamatergic synapse & 24 & $8.70 \mathrm{E}-08$ & $\begin{array}{l}\text { PRKCA, DLGAP1, GNAO1, ADCY2, GRIN1, GRIN2A, PPP3R1, PRKCG, GRIA3, HOMER1, SHANK2, KCNJ3, PRKCB, SLC17A7, GRM5, MAPK1, } \\
\text { PLA2G4A, SLCIA2, GRIN2B, GRIA2, GRM7, PPP3CB, PLCB1, SLCIA1 }\end{array}$ & 114 & 6879 & 3.657 & $2.141 \mathrm{E}-05$ & $7.138 \mathrm{E}-06$ & $1.128 \mathrm{E}-04$ \\
\hline $\begin{array}{l}\text { hsa04723:Retrograde endocannabinoid } \\
\text { signaling }\end{array}$ & 22 & $1.87 \mathrm{E}-07$ & $\begin{array}{l}\text { PRKCA, GABRA2, ADCY2, GNAOI, GABRB3, PTGS2, GABRA4, GABRA3, GABRB1, GABRA5, PRKCG, GRIA3, KCNJ3, PRKCB, SLC17A7, GRM5, } \\
\text { MAPK1, NAPEPLD, KCNJ6, GRIA2, MAPK13, PLCB1 }\end{array}$ & 101 & 6879 & 3.784 & $4.602 \mathrm{E}-05$ & $1.150 \mathrm{E}-05$ & $2.424 \mathrm{E}-04$ \\
\hline hsa05031:Amphetamine addiction & 16 & $3.37 \mathrm{E}-06$ & PRKCA, STX1A, ARC, GRIN1, PPP3R1, GRIN2A, GRIA3, PRKCG, PRKCB, GRIN2B, GRIA2, PPP3CB, CALM3, CREB3L1, SLC18A1, CAMK2A & 66 & 6879 & 4.211 & 8.278E- -04 & $1.656 \mathrm{E}-04$ & $4.362 \mathrm{E}-03$ \\
\hline hsa04020:Calcium signaling pathway & 27 & 9.55E-06 & $\begin{array}{l}\text { ADCY2, PPP3R1, ITPKA, ATP2B1, HRH1, HRH2, PPP3CB, NOS2, PLCB1, CAMK2A, PRKCA, SLC8A1, GRIN1, HTR4, GRIN2A, PRKCG, PRKCB, } \\
\text { P2RX5, GRM5, ADRB1, CHRM3, CHRM2, CHRMI, TBXA2R, CALM3, CACNA1E, HTR2A }\end{array}$ & 179 & 6879 & 2.620 & $2.348 \mathrm{E}-03$ & $3.917 \mathrm{E}-04$ & $1.238 \mathrm{E}-02$ \\
\hline ha05033:Nicotine addiction & 12 & 9.91E-06 & SLC17A7, GABRA2, GRIN2B, GRIA2, GABRB3, GABRA4, GABRA3, GABRB1, GRIN1, GABRA5, GRIN2A, GRIA3 & 40 & 6879 & 5.211 & $2.435 \mathrm{E}-03$ & 3.483E-04 & $1.284 \mathrm{E}-02$ \\
\hline hsa04720:Long-term potentiation & 15 & $1.67 \mathrm{E}-05$ & PRKCA, GRIN1, CREBBP, PPP3RI, GRIN2A, PRKCG, PRKCB, GRM5, MAPK1, GRIA2, GRIN2B, PPP3CB, CALM3, PLCB1, CAMK2A & 66 & 6879 & 3.948 & 4.107E-03 & $5.143 \mathrm{E}-04$ & $2.168 \mathrm{E}-02$ \\
\hline hsa04024:cAMP signaling pathway & 28 & $2.10 \mathrm{E}-05$ & $\begin{array}{l}\text { ADCY2, GABBR2, CNGB1, ATP2B1, BDNF, GRIN2B, CREB3LL, RAPGEF4, CAMK2A, HTR1F, PIK3R1, PTGER2, ROCK1, GRIN1, CREBBP, HTR4, } \\
\text { GRIN2A, GRIA3, PDE4C, NPY1R, MAPK1, ADRB1, NPY, GRIA2, CHRM2, CHRM1, CALM3, GHSR }\end{array}$ & 198 & 6879 & 2.457 & $5.146 \mathrm{E}-03$ & $5.731 \mathrm{E}-04$ & $2.717 \mathrm{E}-02$ \\
\hline hsa04728:Dopaminergic synapse & 21 & $3.57 \mathrm{E}-05$ & $\begin{array}{l}\text { PRKCA, GNAOI, KIF5A, PPP2RSC, GRIN2A, PRKCG, GRIA3, KCNJ3, PRKCB, KCNJ6, GRIN2B, GRIA2, MAPK13, PPP3CB, CALM3, CREB3LI, } \\
\text { SLC18A1, PLCB1, PPP2R2B, CAMK2A, PPP2R2C }\end{array}$ & 128 & 6879 & 2.850 & 8.743E- -03 & $8.778 \mathrm{E}-04$ & 4.625E-02 \\
\hline hsa05032:Morphine addiction & 17 & $5.03 \mathrm{E}-05$ & $\begin{array}{l}\text { PRKCA, GABRA2, ADCY2, GNAO1, GABRA4, GABRB3, GABRA3, GABRB1, GABRA5, PRKCG, PDE4C, GABBR2, KCNJ3, PRKCB, KCNJ6, PDE2A, } \\
\text { PDE8B }\end{array}$ & 91 & 6879 & 3.245 & $1.231 \mathrm{E}-02$ & $1.125 \mathrm{E}-03$ & $6.521 \mathrm{E}-02$ \\
\hline hsa04725:Cholinergic synapse & 19 & $5.30 \mathrm{E}-05$ & $\begin{array}{l}\text { PRKCA, ADCY2, GNAO1, PRKCG, KCNJ12, KCNJ3, PRKCB, KCNQ5, KCNJ4, MAPK1, KCNQ3, KCNJ6, CHRM3, CHRM2, CHRM1, CREB3L1, PLCB1, } \\
\text { CAMK2A, PIK3R1 }\end{array}$ & 111 & 6879 & 2.973 & 1.295E-02 & $1.086 \mathrm{E}-03$ & $6.864 \mathrm{E}-02$ \\
\hline hsa04713:Circadian entrainment & 17 & 8.63E-05 & PRKCA, ADCY2, GNAO1, GRIN1, GRIN2A, GRIA3, PRKCG, KCNJ3, PRKCB, MAPK1, KCNJ6, GRIN2B, GRIA2, CALM3, GUCY1B3, PLCB1, CAMK2A & 95 & 6879 & 3.109 & $2.101 \mathrm{E}-02$ & $1.632 \mathrm{E}-03$ & $1.118 \mathrm{E}-01$ \\
\hline hsa04010:MAPK signaling pathway & 30 & $2.57 \mathrm{E}-04$ & $\begin{array}{l}\text { MEF2C, FGF8, PPP3R1, CACNB1, FGF13, BDNF, PAK2, SOS2, PPP3CB, FGF3, PRKCA, CACNA2D1, CACNG8, NLK, PRKCG, CACNG3, CACNA2D3, } \\
\text { MECOM, PRKCB, MAPK1, PLA2G4A, DUSP2, RASGRF2, MAPK13, IKBKG, NTRK2, CACNAIE, DUSP8, DUSP7, DUSP6 }\end{array}$ & 253 & 6879 & 2.060 & $6.120 \mathrm{E}-02$ & 4.500E-03 & $3.321 \mathrm{E}-01$ \\
\hline $\begin{array}{l}\text { hsa04261: Adrenergic signaling in } \\
\text { cardiomyocytes }\end{array}$ & 20 & $3.11 \mathrm{E}-04$ & $\begin{array}{l}\text { PRKCA, CACNA2D1, ADCY2, CACNG8, PPP2R5C, CACNB1, CACNG3, CACNA2D3, TNNT2, ATP2B1, MAPK1, ADRB1, MAPK13, CALM3, CREB3L1, } \\
\text { RAPGEF4, PLCB1, PPP2R2B, CAMK2A, PPP2R2C }\end{array}$ & 138 & 6879 & 2.518 & $7.370 \mathrm{E}-02$ & $5.091 \mathrm{E}-03$ & $4.025 \mathrm{E}-01$ \\
\hline hsa04726:Serotonergic synapse & 17 & $5.48 \mathrm{E}-04$ & PRKCA, GNAOI, PTGS2, GABRB3, GABRBI, HTR4, PRKCG, KCNJ3, PRKCB, MAPK1, PLA2G4A, KCNJ6, SLC18AI, PLCB1, HTR3B, HTRIF, HTR2A & 111 & 6879 & 2.660 & $1.261 \mathrm{E}-01$ & $8.390 \mathrm{E}-03$ & $7.076 \mathrm{E}-01$ \\
\hline hsa04360:Axon guidance & 18 & $8.84 \mathrm{E}-04$ & $\begin{array}{l}\text { NGEF, ROCK1, EFNB33, PPP3R1, NTN4, NTNG2, LRRC4C, SLIT1, NCK2, SEMA5B, EPHA4, MAPK1, EPHB6, RND1, PAK2, SEMA4G, SEMA4C, } \\
\text { PPP3CB }\end{array}$ & 127 & 6879 & 2.462 & $1.956 \mathrm{E}-01$ & $1.272 \mathrm{E}-02$ & $1.140 \mathrm{E}+00$ \\
\hline hsa04911:Insulin secretion & 14 & $1.02 \mathrm{E}-03$ & PRKCA, KCNMA1, STX1A, ADCY2, FFAR1, PRKCG, KCNMB1, PRKCB, CHRM3, KCNN1, CREB3L1, RAPGEF4, PLCB1, CAMK2A & 85 & 6879 & 2.861 & $2.217 \mathrm{E}-01$ & $1.383 \mathrm{E}-02$ & $1.312 \mathrm{E}+00$ \\
\hline $\begin{array}{l}\text { hsa04750:Inflammatory mediator } \\
\text { regulation of TRP channels }\end{array}$ & 15 & $1.31 \mathrm{E}-03$ & PRKCA, PTGER2, ADCY2, PRKCG, PRKCB, PLA2G4A, HRH1, MAPK13, ILIRAP, CALM3, PLA2G6, PLCB1, CAMK2A, PIK3R1, HTR2A & 98 & 6879 & 2.659 & $2.760 \mathrm{E}-01$ & $1.686 \mathrm{E}-02$ & $1.687 \mathrm{E}+00$ \\
\hline hsa04730:Long-term depression & 11 & $1.98 \mathrm{E}-03$ & CRHR1, PRKCA, MAPK1, PLA2G4A, GNAOI, GRIA2, GRIA3, GUCY1B3, PRKCG, PLCB1, PRKCB & 60 & 6879 & 3.185 & $3.856 \mathrm{E}-01$ & $2.406 \mathrm{E}-02$ & $2.533 \mathrm{E}+00$ \\
\hline
\end{tabular}




\begin{tabular}{|c|c|c|c|c|c|c|c|c|c|}
\hline hsa04727:GABAergic synapse & 13 & $3.15 \mathrm{E}-03$ & PRKCA, GABRA2, GNAO1, ADCY2, GABRA4, GABRB3, GABRA3, GABRB1, GABRA5, PRKCG, GABBR2, PRKCB, KCNJ6 & 85 & 6879 & 2.657 & $5.403 \mathrm{E}-01$ & $3.633 \mathrm{E}-02$ & $4.011 \mathrm{E}+00$ \\
\hline hsa04970:Salivary secretion & 13 & 3.48E-03 & PRKCA, ATP2B1, KCNMA1, ADCY2, ADRB1, CHRM3, AQP5, CALM3, GUCY1B3, PRKCG, TRPV6, PLCB1, PRKCB & 86 & 6879 & 2.626 & $5.759 \mathrm{E}-01$ & $3.824 \mathrm{E}-02$ & $4.418 \mathrm{E}+0 \mathrm{C}$ \\
\hline hsa04022:cGMP-PKG signaling pathway & 19 & $3.98 \mathrm{E}-03$ & $\begin{array}{l}\text { KCNMA1, MEF2C, SLC8A1, MEF2A, ADCY2, ROCK1, PPP3R1, CNGB1, IRS1, KCNMB1, ATP2B1, MAPK1, ADRB1, PDE2A, PPP3CB, CALM3, } \\
\text { CREB3L1, GUCY1B3, PLCB1 }\end{array}$ & 158 & 6879 & 2.089 & 6.247E-01 & 4.171E-02 & $5.031 \mathrm{E}+0 \mathrm{C}$ \\
\hline hsa04014:Ras signaling pathway & 24 & $5.14 \mathrm{E}-03$ & $\begin{array}{l}\text { PRKCA, FGF8, GRIN1, GRIN2A, PRKCG, FGF13, HGF, PRKCB, RASAL2, RASAL1, MAPK1, PLA2G4A, PAK2, GRIN2B, RASGRF2, ETS2, IKBKG, } \\
\text { SOS2, CALM3, PLA2G6, SYNGAP1, SHC3, FGF3, PIK3R1 }\end{array}$ & 226 & 6879 & 1.845 & 7.183E-01 & $5.142 \mathrm{E}-02$ & $6.456 \mathrm{E}+0 \mathrm{C}$ \\
\hline hsa05030:Cocaine addiction & 9 & $6.23 \mathrm{E}-03$ & CDK5R1, BDNF, GRIN2B, GRIA2, GRIN1, GPSM1, GRIN2A, CREB3L1, SLCI8AI & 49 & 6879 & 3.191 & $7.850 \mathrm{E}-01$ & $5.964 \mathrm{E}-02$ & $7.778 \mathrm{E}+00$ \\
\hline $\begin{array}{l}\text { hsa04925:Aldosterone synthesis and } \\
\text { seceretion }\end{array}$ & 12 & $6.23 \mathrm{E}-03$ & PRKCA, ADCY2, CAMK1G, PDE2A, STAR, CAMK1, CALM3, CREB3L1, PRKCG, PLCB1, CAMK2A, PRKCB & 81 & 6879 & 2.574 & 7.852E-01 & $5.743 \mathrm{E}-02$ & $7.781 \mathrm{E}+0 \mathrm{C}$ \\
\hline $\begin{array}{l}\text { hsa04270:Vascular smooth muscle } \\
\text { contraction }\end{array}$ & 15 & 6.87E- -03 & PRKCA, KCNMA1, RAMP2, ADCY2, ROCK1, PRKCG, KCNMB1, PRKCB, MAPK1, PTGIR, PLA2G4A, PLA2G6, CALM3, GUCY1B3, PLCB1 & 117 & 6879 & 2.227 & $8.164 \mathrm{E}-01$ & $6.085 \mathrm{E}-02$ & $8.542 \mathrm{E}+0 \mathrm{C}$ \\
\hline $\begin{array}{l}\text { hsa05014:Amyotrophic lateral sclerosis } \\
\text { (ALS) }\end{array}$ & 9 & $7.06 \mathrm{E}-03$ & SLC1A2, GRIN2B, GRIA2, MAPK13, GRIN1, PPP3CB, PPP3R1, GRIN2A, NEFM & 50 & 6879 & 3.127 & $8.248 \mathrm{E}-01$ & $6.031 \mathrm{E}-02$ & $8.766 \mathrm{E}+0 \mathrm{C}$ \\
\hline hsa04370:VEGF signaling pathway & 10 & 7.52E- -03 & PRKCA, MAPK1, PLA2G4A, PTGS2, MAPK13, PPP3CB, PPP3R1, PRKCG, PIK3RI, PRKCB & 61 & 6879 & 2.848 & $8.440 \mathrm{E}-01$ & 6.205E-02 & $9.321 \mathrm{E}+0 \mathrm{C}$ \\
\hline hsa04971:Gastric acid secretion & 11 & $8.40 \mathrm{E}-03$ & PRKCA, ADCY2, CHRM3, HRH2, CALM3, PRKCG, GAST, PLCB1, CAMK2A, KCNK2, PRKCB & 73 & 6879 & 2.618 & 8.745E-01 & $6.684 \mathrm{E}-02$ & $1.035 \mathrm{E}+01$ \\
\hline hsa04015:Rap1 signaling pathway & 22 & $8.91 \mathrm{E}-03$ & $\begin{array}{l}\text { PRKCA, FGF8, ADCY2, GNAO1, MAGI1, TLN2, GRIN1, GRIN2A, PRKCG, FGF13, HGF, RGS14, PRKCB, MAPK1, GRIN2B, LPAR5, MAPK13, CALM3, } \\
\text { RAPGEF4, PLCB1, PIK3R1, FGF3 }\end{array}$ & 210 & 6879 & 1.820 & 8.894E-01 & $6.856 \mathrm{E}-02$ & $1.095 \mathrm{E}+01$ \\
\hline hsa04068:FoxO signaling pathway & 16 & $9.61 \mathrm{E}-03$ & NLK, CREBBP, PRKAB2, SMAD3, HOMER1, IRS1, MAPK1, G6PC, CDKN1B, PLK2, CCND2, MAPK13, FOXG1, SOS2, AGAP2, PIK3R1 & 134 & 6879 & 2.074 & $9.069 \mathrm{E}-01$ & $7.151 \mathrm{E}-02$ & $1.176 \mathrm{E}+01$ \\
\hline hsa04012:ErbB signaling pathway & 12 & $1.06 \mathrm{E}-02$ & PRKCA, MAPK1, NCK2, CDKN1B, NRG3, PAK2, SOS2, PRKCG, SHC3, CAMK2A, PIK3R1, PRKCB & 87 & 6879 & 2.396 & 9.271E-01 & 7.630E-02 & $1.289 \mathrm{E}+01$ \\
\hline hsa05214:Glioma & 10 & $1.13 \mathrm{E}-02$ & PRKCA, MAPK1, E2F3, SOS2, CALM3, PRKCG, SHC3, CAMK2A, PIK3R1, PRKCB & 65 & 6879 & 2.672 & 9.395E-01 & 7.919E-02 & $1.374 \mathrm{E}+01$ \\
\hline hsa04916:Melanogenesis & 13 & $1.16 \mathrm{E}-02$ & PRKCA, MAPK1, TYRP1, GNAO1, ADCY2, CREBBP, CALM3, CREB3L1, PRKCG, PLCB1, WNT7A, CAMK2A, PRKCB & 100 & 6879 & 2.258 & 9.437E-01 & 7.891E-02 & 1.406E+01 \\
\hline hsa04310:Wnt signaling pathway & 16 & $1.24 \mathrm{E}-02$ & PRKCA, NLK, CREBBP, PPP3R1, PRKCG, PRKCB, DKK4, SOST, PRICKLE1, CCND2, PRICKLE2, PPP3CB, WIFI, PLCB1, WNT7A, CAMK2A & 138 & 6879 & 2.014 & $9.539 \mathrm{E}-01$ & $8.190 \mathrm{E}-02$ & $1.496 \mathrm{E}+01$ \\
\hline hsa04912:GnRH signaling pathway & 12 & $1.46 \mathrm{E}-02$ & PRKCA, MAPK1, PLA2G4A, ADCY2, MAPK13, GNRH2, SOS2, CALM3, PLCB1, CAMK2A, LHB, PRKCB & 91 & 6879 & 2.291 & $9.731 \mathrm{E}-01$ & $9.312 \mathrm{E}-02$ & $1.735 \mathrm{E}+01$ \\
\hline $\begin{array}{l}\text { hsa05142:Chagas disease (American } \\
\text { trypanosomiasis) }\end{array}$ & 13 & $1.56 \mathrm{E}-02$ & MAPK1, GNAO1, CD3E, MAPK13, IKBKG, SMAD3, NOS2, PLCB1, PPP2R2B, IFNGR2, PPP2R2C, PIK3R1, TLR9 & 104 & 6879 & 2.171 & 9.790E-01 & $9.669 \mathrm{E}-02$ & 1.842E+01 \\
\hline hsa04611:Platelet activation & 15 & $1.66 \mathrm{E}-02$ & ADCY2, ROCK1, TLN2, GP9, MAPK1, PTGIR, PLA2G4A, MAPK13, COL27A1, TBXA2R, FCER1G, GUCY1B3, PLCB1, COL24A1, PIK3R1 & 130 & 6879 & 2.004 & 9.839E-01 & $1.004 \mathrm{E}-01$ & $1.954 \mathrm{E}+01$ \\
\hline hsa04520:Adherens junction & 10 & $1.96 \mathrm{E}-02$ & PTPRJ, MAPK1, NLK, WASF1, CREBBP, LMO7, SMAD3, ACTN1, WASL, CTNNA2 & 71 & 6879 & 2.447 & $9.922 \mathrm{E}-01$ & $1.144 \mathrm{E}-01$ & $2.258 \mathrm{E}+01$ \\
\hline $\begin{array}{l}\text { hsa04960:Aldosterone-regulated sodium } \\
\text { reabsorption }\end{array}$ & 7 & $2.25 \mathrm{E}-02$ & PRKCA, MAPK1, PRKCG, IRS1, SLC9A3R2, PIK3R1, PRKCB & 39 & 6879 & 3.118 & $9.963 \mathrm{E}-01$ & $1.276 \mathrm{E}-01$ & $2.553 \mathrm{E}+01$ \\
\hline hsa04915:Estrogen signaling pathway & 12 & $2.59 \mathrm{E}-02$ & MAPK1, GNAO1, ADCY2, KCNJ6, SOS2, CALM3, CREB3L1, GABBR2, PLCB1, SHC3, KCNJ3, PIK3R1 & 99 & 6879 & 2.106 & 9.984E-01 & $1.424 \mathrm{E}-01$ & $2.881 \mathrm{E}+01$ \\
\hline hsa05200:Pathways in cancer & 33 & $2.71 \mathrm{E}-02$ & $\begin{array}{l}\text { E2F3, FGF8, ADCY2, PTGS2, ARNT2, FGF13, LAMB33, SOS2, CSF3R, RARA, NOS2, PLCB I, TRAF5, FGF3, PIK3R1, PRKCA, PTGER2, ROCK1, KLK3, } \\
\text { CREBBP, SMAD3, PRKCG, HGF, BIRC3, MECOM, PRCB, CTNNA2, DAPK1, MAPK1, CDKNIB, LPAR5, IKBKG, WNT7A }\end{array}$ & 393 & 6879 & 1.459 & 9.989E-01 & $1.457 \mathrm{E}-01$ & $3.000 \mathrm{E}+01$ \\
\hline hsa04540:Gap junction & 11 & $2.86 \mathrm{E}-02$ & PRKCA, GRM5, MAPK1, ADCY2, ADRB1, SOS2, GUCY1B3, PRKCG, PLCB1, PRKCB, HTR2A & 88 & 6879 & 2.171 & 9.992E-01 & $1.497 \mathrm{E}-01$ & 3.134E+01 \\
\hline hsa05231:Choline metabolism in cancer & 12 & 2.95E-02 & PRKCA, MAPK1, PLA2G4A, DGKB, SLC44AS, WASFI, SOS2, PRKCG, WASL, DGKI, PIK3R1, PRKCB & 101 & 6879 & 2.064 & 9.994E-01 & $1.510 \mathrm{E}-01$ & $3.216 \mathrm{E}+01$ \\
\hline hsa04810:Regulation of actin cytoskeleton & 20 & $3.22 \mathrm{E}-02$ & $\begin{array}{l}\text { ARHGEF4, FGD1, FGF8, ROCK1, WASF1, DIAPH2, IQGAP3, ABI2, ACTN1, FGF13, MAPK1, PAK2, CHRM3, CHRM2, CHRM1, SOS2, MOS, WASL, } \\
\text { FGF3, PIK3R1 }\end{array}$ & 210 & 6879 & 1.654 & 9.997E-01 & 1.605E-01 & $3.456 \mathrm{E}+01$ \\
\hline hsa04062:Chemokine signaling pathway & 18 & $3.80 \mathrm{E}-02$ & ADCY2, ROCK1, NFKBIB, CX3CL1, CCL24, CCR9, MAPK1, CCL22, PPBP, CXCL14, CCL21, IKBKG, SOS2, WASL, PLCB1, SHC3, XCR1, PIK3R1 & 186 & 6879 & 1.681 & $9.999 \mathrm{E}-01$ & $1.837 \mathrm{E}-01$ & $3.949 \mathrm{E}+01$ \\
\hline hsa05143:African trypanosomiasis & 6 & 3.83E-02 & PRKCA, APOA1, PRKCG, PLCB1, PRKCB, TLR9 & 33 & 6879 & 3.158 & 9.999E-01 & $1.813 \mathrm{E}-01$ & $3.970 \mathrm{E}+01$ \\
\hline $\begin{array}{l}\text { hsa049233:Regulation of lipolysis in } \\
\text { adipocytes }\end{array}$ & 8 & 3.99E-02 & ADCY2, ADRB1, NPY, PTGS2, TSHB, NPYIR, IRS1, PIK3R1 & 56 & 6879 & 2.482 & $1.000 \mathrm{E}+00$ & $1.848 \mathrm{E}-01$ & $4.099 \mathrm{E}+01$ \\
\hline hsa05223:Non-small cell lung cancer & 8 & 3.99E-02 & PRKCA, FHIT, MAPK1, E2F3, SOS2, PRKCG, PIK3R1, PRKCB & 56 & 6879 & 2.482 & $1.000 \mathrm{E}+00$ & $1.848 \mathrm{E}-01$ & 4.099E+01 \\
\hline hsa04071:Sphingolipid signaling pathway & 13 & $4.20 \mathrm{E}-02$ & PRKCA, SIPR2, MAPK1, ROCK1, MAPK13, PPP2R5C, FCER1G, PRKCG, PLCB1, PPP2R2B, PPP2R2C, PIK3R1, PRKCB & 120 & 6879 & 1.882 & $1.000 \mathrm{E}+00$ & $1.905 \mathrm{E}-01$ & $4.268 \mathrm{E}+01$ \\
\hline $\begin{array}{l}\text { hsa000334:Glycosaminoglycan biosynthesis } \\
\text { - heparan sulfate / heparin }\end{array}$ & 5 & $4.57 \mathrm{E}-02$ & HS3ST3A1, HS3ST2, HS6ST3, EXTL1, HS2ST1 & 24 & 6879 & 3.619 & $1.000 \mathrm{E}+00$ & $2.019 \mathrm{E}-01$ & $4.545 \mathrm{E}+01$ \\
\hline $\begin{array}{l}\text { hsa04650:Natural killer cell mediated } \\
\text { cylotoxicity }\end{array}$ & 13 & $4.68 \mathrm{E}-02$ & PRKCA, PPP3R1, PRKCG, PRKCB, MAPK1, ULBP1, SOS2, PPP3CB, FCER1G, SHC3, SH2D1B, IFNGR2, PIK3R1 & 122 & 6879 & 1.851 & $1.000 \mathrm{E}+00$ & $2.028 \mathrm{E}-01$ & 4.624E+01 \\
\hline hsa04066:HIF-1 signaling pathway & 11 & 4.79E-02 & PRKCA, MAPK1, CDKN1B, CREBBP, PRKCG, NOS2, CAMK2A, IFNGR2, PIK3R1, NPPA, PRKCB & 96 & 6879 & 1.990 & $1.000 \mathrm{E}+00$ & 2.036E-01 & $4.704 \mathrm{E}+01$ \\
\hline hsa05222:Small cell lung cancer & 10 & 5.39E- -02 & FHIT, E2F3, LAMB3, CDKN1B, PTGS2, IKBKG, NOS2, BIRC3, TRAF5, PIK3R1 & 85 & 6879 & 2.044 & $1.000 \mathrm{E}+00$ & 2.231E-01 & $5.123 \mathrm{E}+01$ \\
\hline hsa04922:Glucagon signaling pathway & 11 & 5.69E-02 & CPTIC, G6PC, ADCY2, PRKAB2, CREBBP, PPP3CB, PPP3R1, CALM3, CREB3L1, PLCB1, CAMK2A & 99 & 6879 & 1.930 & $1.000 \mathrm{E}+00$ & 2.306E-01 & $5.321 \mathrm{E}+01$ \\
\hline hsa04660: T cell receptor signaling pathway & 11 & $6.02 \mathrm{E}-02$ & MAPK1, NCK2, PAK2, CD3E, MAPK13, NFKBIB, SOS2, IKBKG, PPP3CB, PPP3R1, PIK3R1 & 100 & 6879 & 1.911 & $1.000 \mathrm{E}+00$ & 2.386E-01 & $5.526 \mathrm{E}+01$ \\
\hline hsa05161:Hepatitis B & 14 & $7.26 \mathrm{E}-02$ & PRKCA, EGR3, E2F3, EGR2, CREBBP, YWHAB, PRKCG, PRKCB, STAT6, MAPK1, CDKNIB, IKBKG, CREB3LI, PIK3RI & 145 & 6879 & 1.677 & $1.000 \mathrm{E}+00$ & $2.775 \mathrm{E}-01$ & $6.232 \mathrm{E}+01$ \\
\hline hsa04924:Renin secretion & 8 & 7.27E-02 & KCNMA1, PTGER2, ADRB1, PPP3CB, PPP3R1, CALM3, GUCY1B3, PLCB1 & 64 & 6879 & 2.171 & $1.000 \mathrm{E}+00$ & 2.740E-01 & $6.240 \mathrm{E}+01$ \\
\hline hsa05146:Amoebiasis & 11 & $8.22 \mathrm{E}-02$ & PRKCA, ARG1, LAMB3, COL27A1, ACTN1, PRKCG, NOS2, PLCB1, COL24A1, PIK3R1, PRKCB & 106 & 6879 & 1.803 & $1.000 \mathrm{E}+00$ & $3.007 \mathrm{E}-01$ & $6.710 \mathrm{E}+01$ \\
\hline hsa04510:Focal adhesion & 18 & $8.28 \mathrm{E}-02$ & PRKCA, ROCK1, TLN2, ACTN1, PRKCG, HGF, BIRC3, PRKCB, MAPK1, LAMB3, PAK2, CCND2, COL27A1, SOS2, COL6A3, SHC3, COL24A1, PIK3R1 & 206 & 6879 & 1.518 & $1.000 \mathrm{E}+00$ & 2.983E-01 & $6.735 \mathrm{E}+01$ \\
\hline hsa04722:Neurotrophin signaling pathway & 12 & $8.29 \mathrm{E}-02$ & MAPK1, BDNF, MAPK13, NFKBIB, NTRK2, SOS2, CALM3, SHC3, CAMK2A, IRS1, PIK3R1, MATK & 120 & 6879 & 1.737 & $1.000 \mathrm{E}+00$ & 2.945E-01 & $6.741 \mathrm{E}+01$ \\
\hline hsa04972:Pancreatic secretion & 10 & $8.50 \mathrm{E}-02$ & PRKCA, ATP2B1, KCNMA1, ADCY2, CHRM3, PRKCG, PLCB1, RAB27B, PRKCB, CTRL & 93 & 6879 & 1.868 & $1.000 \mathrm{E}+00$ & 2.969E-01 & $6.835 \mathrm{E}+01$ \\
\hline hsa04151:PI3K-Akt signaling pathway & 27 & $9.10 \mathrm{E}-02$ & $\begin{array}{l}\text { CSH1, FGF8, PPP2R5C, FGF13, LAMB3, COL27A1, SOS2, COL6A33, CSF3R, CREB3L1, PPP2R2B, PPP2R2C, FGF3, PIK3R1, PRKCA, YWHAB, HGF, } \\
\text { IRS1, MAPK1, G6PC, CDKN1B, LPAR5, CCND2, CHRM2, CHRM1, IKBKG, COL24A1 }\end{array}$ & 345 & 6879 & 1.359 & $1.000 \mathrm{E}+00$ & 3.109E-01 & $7.094 \mathrm{E}+01$ \\
\hline hsa04664:Fc epsilon RI signaling pathway & 8 & 9.37E-02 & PRKCA, MAPKI, PLA2G4A, MAPK13, SOS2, FCERIG, PIK3R1, PRKCB & 68 & 6879 & 2.044 & $1.000 \mathrm{E}+00$ & $3.150 \mathrm{E}-01$ & $7.207 \mathrm{E}+01$ \\
\hline hsa04662:B cell receptor signaling pathway & 8 & $9.95 \mathrm{E}-02$ & MAPK1, CR2, NFKBIB, SOS2, IKBKG, PPP3CB, PPP3R1, PIK3R1 & 69 & 6879 & 2.014 & $1.000 \mathrm{E}+00$ & $3.274 \mathrm{E}-01$ & $7.428 \mathrm{E}+01$ \\
\hline
\end{tabular}

Table 2

Key:

Yellow - Pathways that are involved in neuroplasticity

Blue - Pathways involved in other systems hypothesized to contribute to the pathophysiology of depression

Red - Pathways that are potentially involved in depression but have limited and/or dated literature backing them 
Purple- Gene sets containing genes associated with depression from Table 1

Several notable pathways appear. Of course, the glutamatergic synapse is one of them.

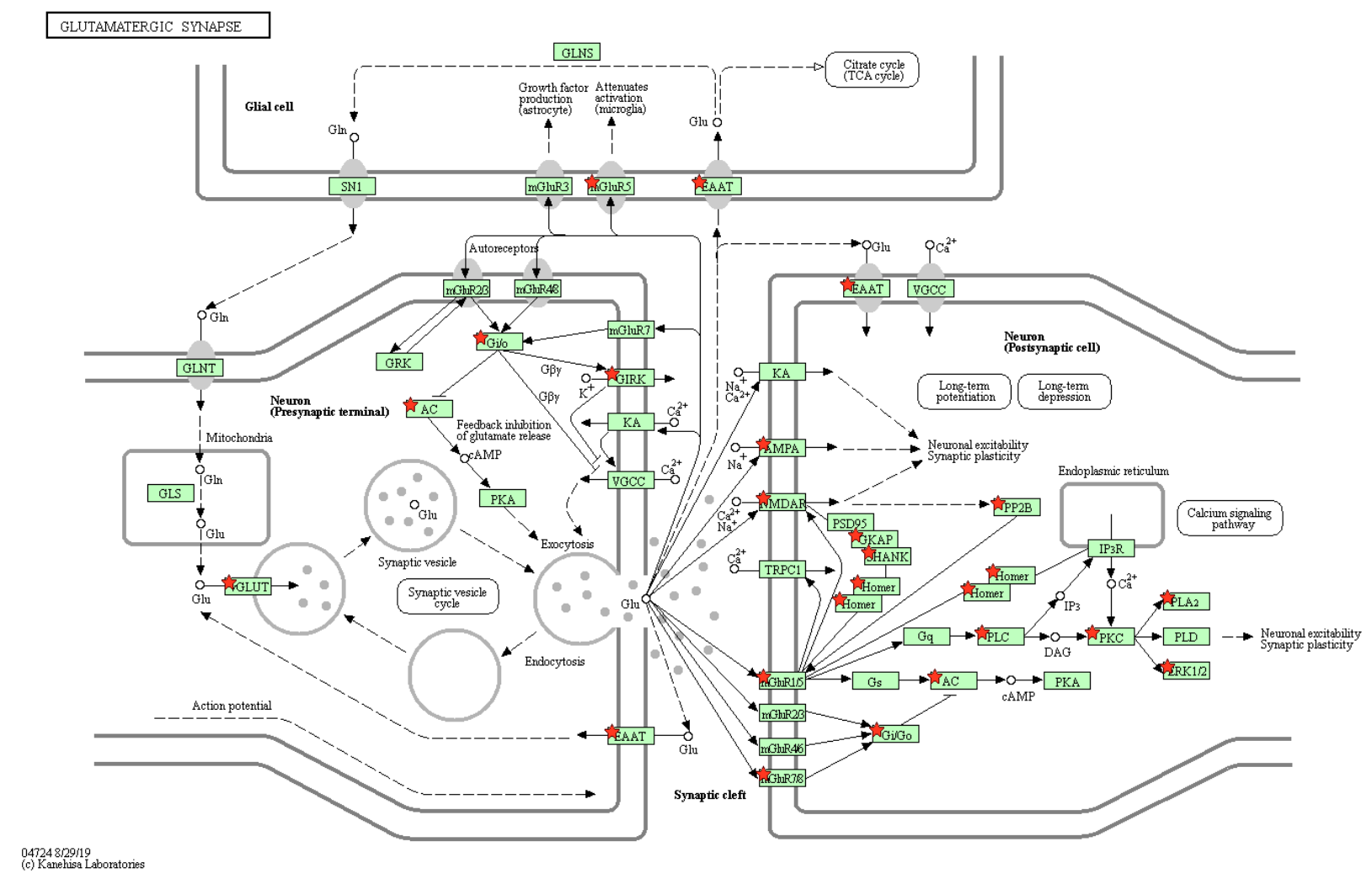

The mechanism of NMDAR-mediated excitotoxicity is excessive calcium intake into the postsynaptic neuron, and this is done by increased mGluR $1 / 5$ activity. mGluR $1 / 5$ has also been shown to upregulate NMDARs [14]. A possible therapeutic mechanism would be inhibition of mGluR1/5.

The role of AMPA receptors complicates the role of glutamate in neuroplasticity. Activation of AMPA receptors with glutamate actually increases BDNF release and neuroplasticity [15], and ketamine appears to increase prefrontal glutamate levels [16]. The disinhibition hypothesis states that ketamine's mechanism of action is actually the result of NMDAR inhibition on GABAergic neurons, which results in less inhibition and indirectly results in the release of more glutamate that activates AMPA receptors. Both mechanisms are possibly at play, with ketamine increasing activation of "good" glutamate receptors while inhibiting "bad" ones. Following this idea, several mechanisms increase synaptic glutamate: inhibition of mGlur $2 / 3$ or mGlur $4 / 8$, inhibition of KCNJ3 channels (labeled GIRK in the picture), or inhibition of SLC1A7/2 channels (labeled EAAT in the picture). 
Several downstream protein cascades of BDNF receptor binding, including Ras, MAPK, and PI3K-Akt pathways, were also enriched.

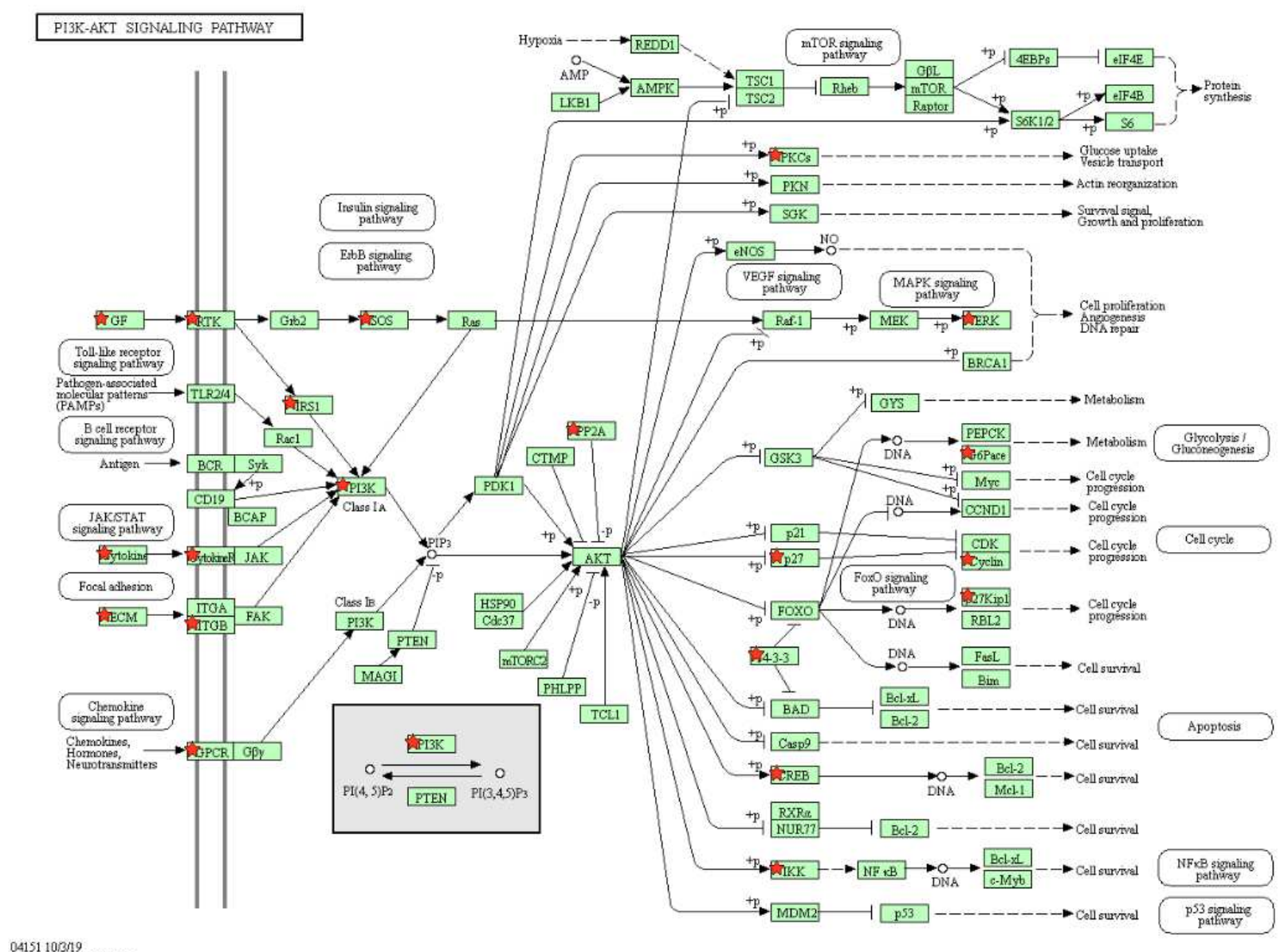

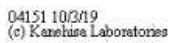

Akt signaling activates mTOR, which then induces synaptic protein synthesis and neuroplasticity. This pathway is hypothesized to be a part of ketamine's mechanism of action $[17,18]$. Consistent with this idea and the neuroplasticity hypothesis, inhibiting mTOR should lessen ketamine's efficacy, but results have been contradictory. Inhibiting mTOR with rapamycin completely blocked ketamine-induced synaptogenesis in rats [17], yet in depressed patients rapamycin actually prolonged ketamine's antidepressant effects [19].

PI3K-Akt signaling is also activated by IL-2, IL-3, IL-4, IL-6, and IL-7, which also may be worth investigating as a connection to the immune system.

From Table 2, genes associated with depression that are in pathways of interest - gene sets highlighted in purple that also correspond to a highlighted pathway-along with the initial 9 genes make the list for candidate genes. 


\section{Interaction Networks}

\section{$\underline{\text { Pathway Interaction Network }}$}

All pathways in Table 2 were put into Cytoscape, and a network was constructed using EnrichmentMap. Connections are created between pathways if the similarity coefficient $\geq .63$. Lighter-colored nodes represent a higher corresponding q-value with a cutoff value of .05 .

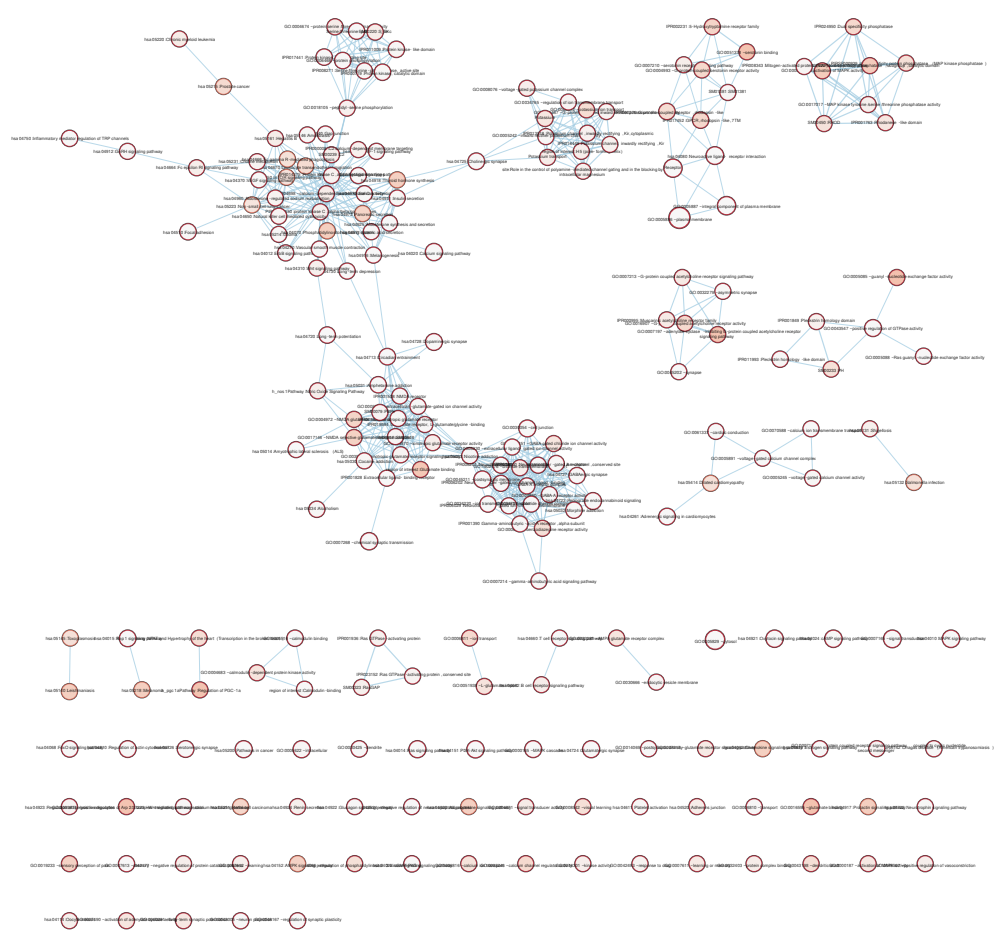

\section{$\underline{\text { Protein Interaction Network }}$}

The initial 9 genes were used to build a protein-protein interaction network in STRING. The network includes first and second shell interactions and is based on experimental evidence using a combined score $\geq 0.40$. The networks were further evaluated in Cytoscape. Subnetworks that connect the products of the initial 9 genes were identified using Cytohubba. 

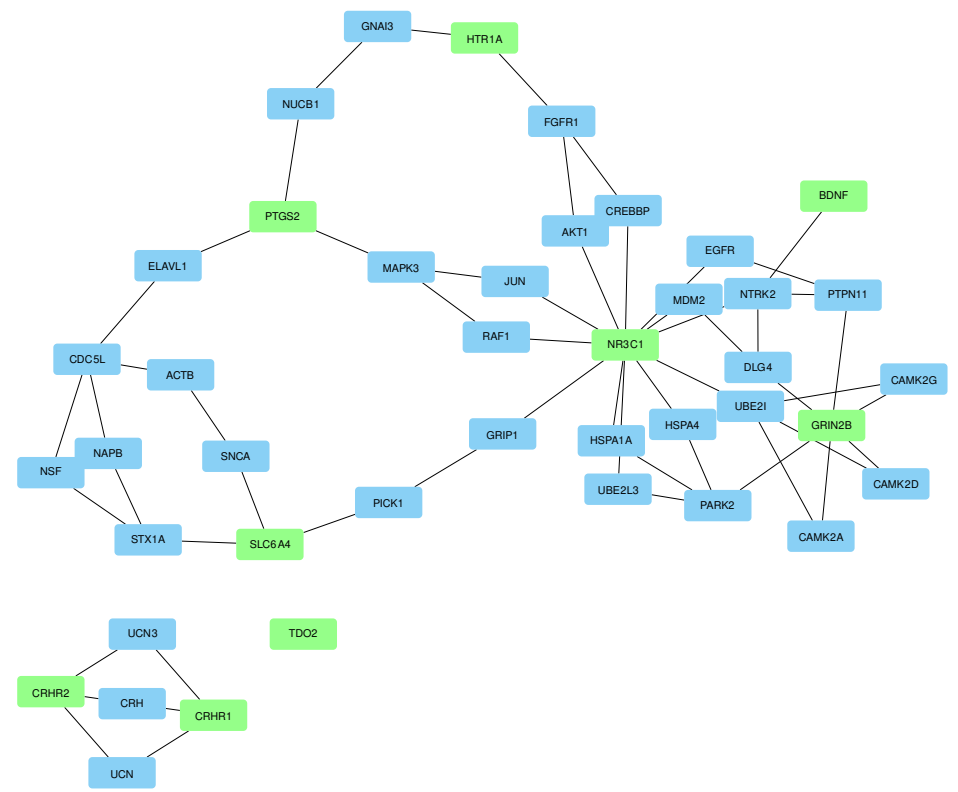

Expanding the subnetwork to also include proteins that directly interact with the products of the initial 9 genes yields the network below.
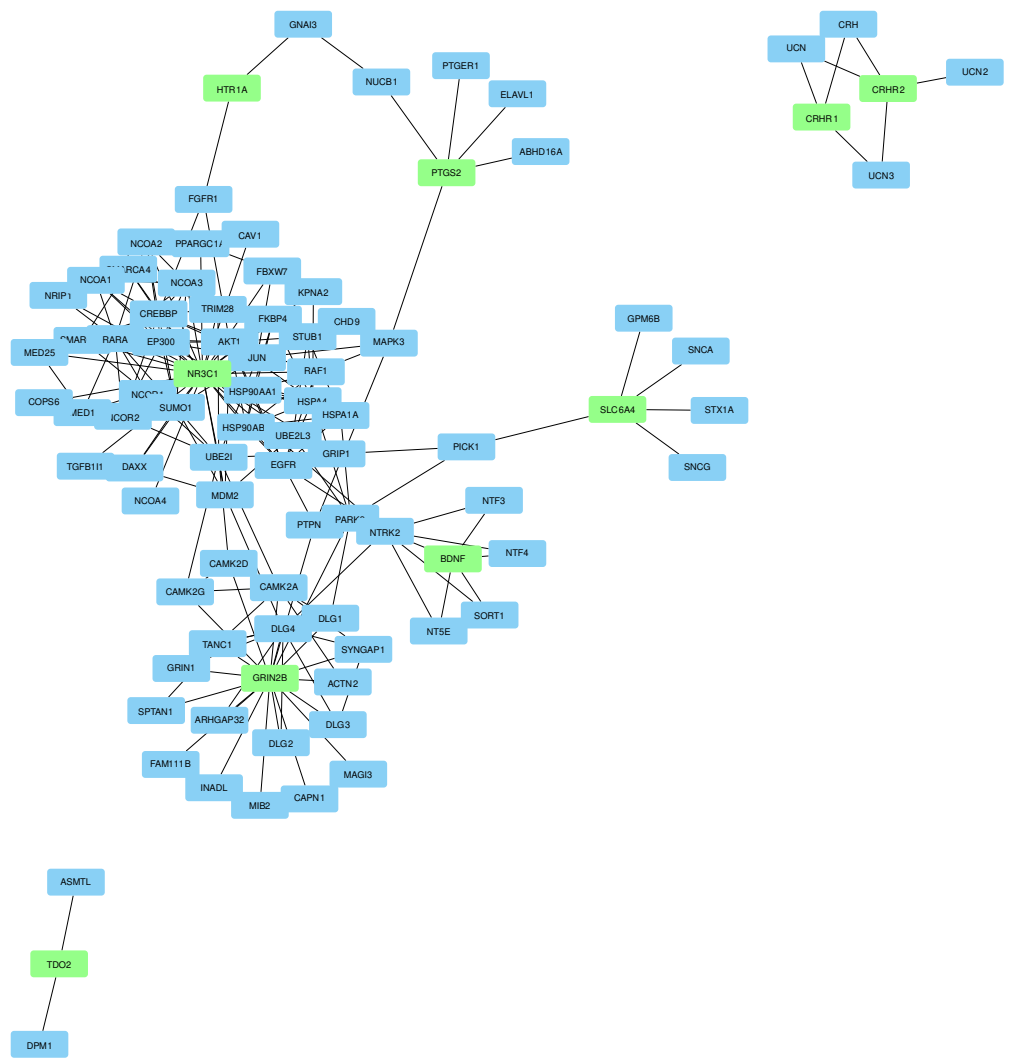

Note how genes part of the serotonergic system (SLC6A4, HTR1A), glutamatergic system \& neuroplasticity (BDNF, GRIN2B), neuroinflammation (PTGS2), and the stress response (NR3C1) are in the same subnetwork. This is not surprising because these are all systems in the 
brain directly involved with the pathophysiology of depression. The HPA axis (CRH1, CRH2) except for $\mathrm{NR} 3 \mathrm{C} 1$, the glucocorticoid receptor - and the kynurenine pathway (TDO2) are not connected to the larger subnetwork. Again, this is not unexpected because the depressive effects of $\mathrm{CRH}$ and the metabolism of tryptophan are indirect.

MCODE was used to identify subnetworks that are highly connected. The top 4 subnetworks are displayed along with the initial 9 genes on the right. All 4 subnetworks are connected to the glucocorticoid receptor, which controls gene expression. All 4 subnetworks are distinct biological systems.

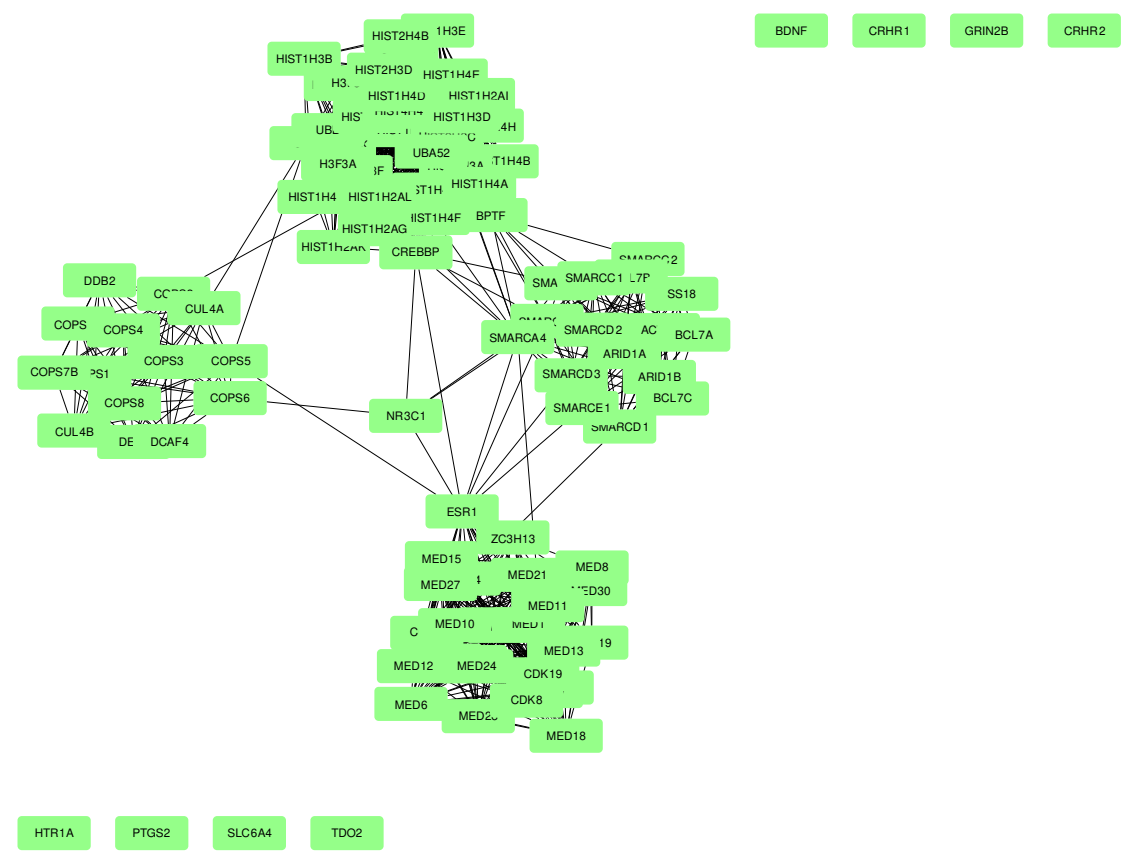

Of course, depression has genetic and epigenetic influences. $\mathrm{NR} 3 \mathrm{C} 1$ is a nuclear transcription factor and likely mediates stress-induced epigenetic changes associated with depression, and specific histone genes are identified.

The COP9 signalosome complex is still not well understood and an area of current research. The tricyclic antidepressant imipramine upregulates its expression in rats [20].

SWI/SWF chromatin remodeling complexes control gene transcription and may be another mechanism of stress-induced epigenetic changes. They have been implicated in psychiatric diseases [21], including depression [22], and SMARCA3 may be a part of the mechanism of action of SSRIs [23].

The mediator complex is a downstream target of the estrogen receptor, which may be involved in postpartum depression. 
The 6th top MCODE subnetwork is composed of ribosomal genes. Dysfunction of ribosomal gene expression, possibly contributed to by dysfunctional glucocorticoid signaling, has shown to be associated with chronic social defeat [24].

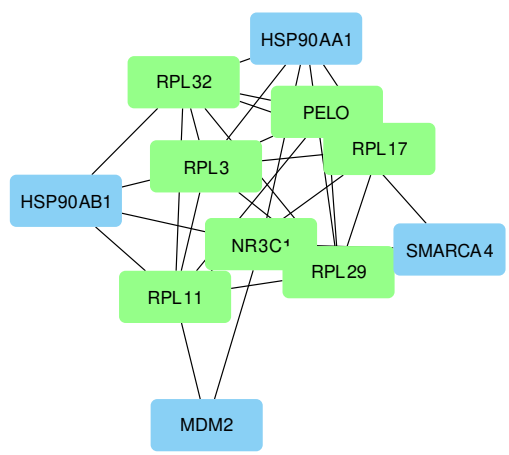

STRING was also used to create a PPI network containing the list of candidate genes and first \& second shell interactions. The network displayed below is a subnetwork that shows connections between the products of candidate genes as well as gene products that directly interact with them. The layout is arranged based on MCODE clusters using clusterMaker. Green colored nodes are candidate genes, and red colored nodes are the initial 9 genes. Red edges are connected to at least 1 initial gene. Darker edges are connections within MCODE clusters. 


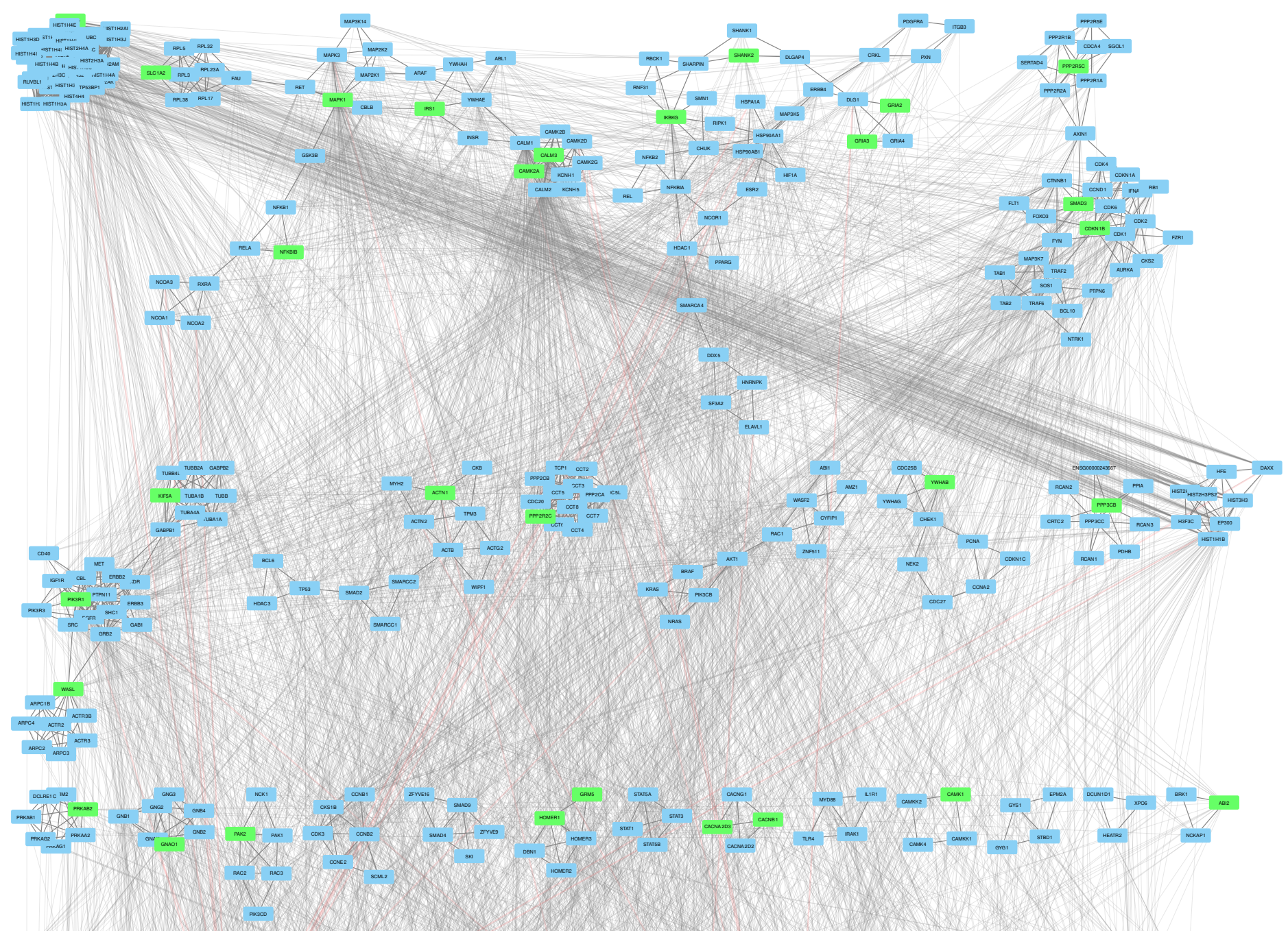

Tran -

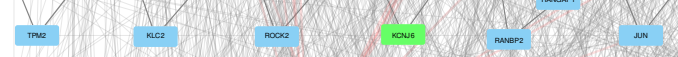

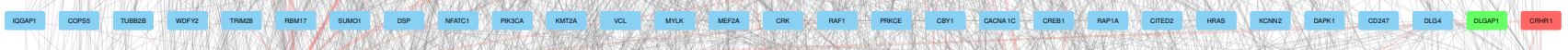

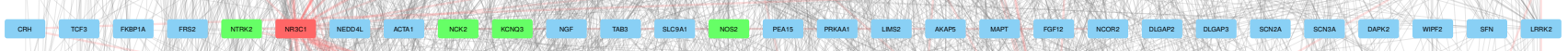

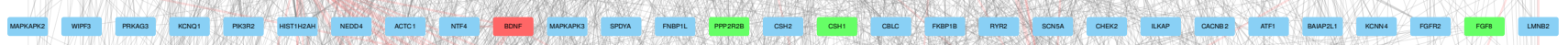

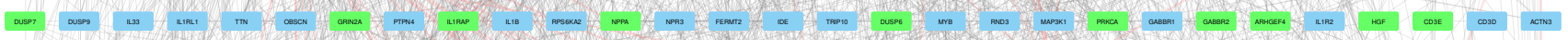

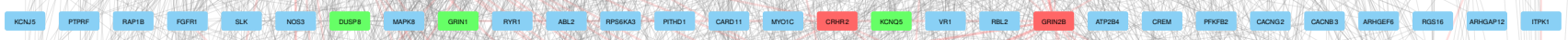

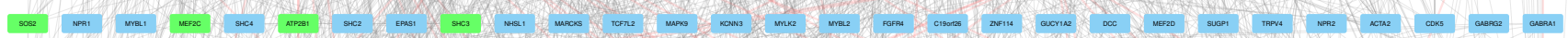

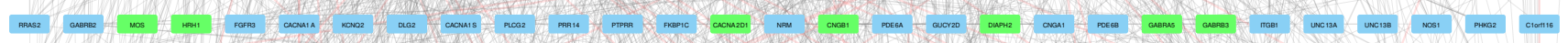

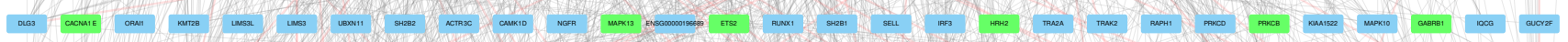

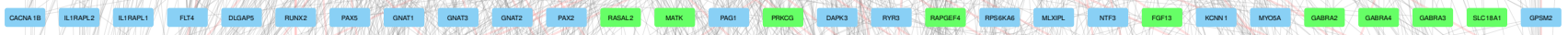

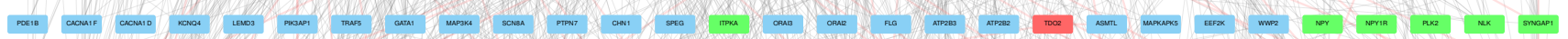

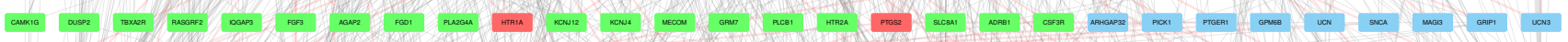

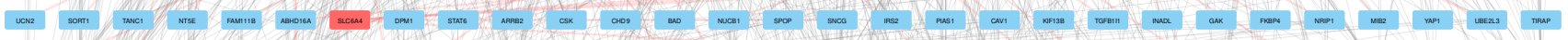

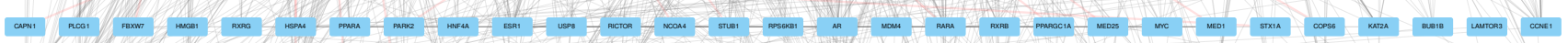

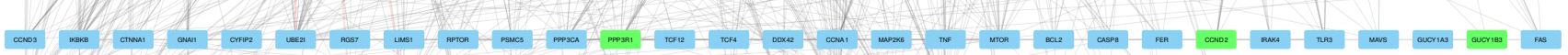

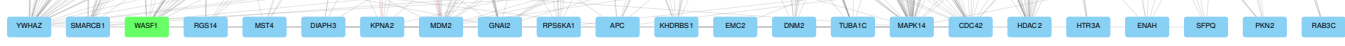

\section{Network 1}


Interesting genes from the MCODE subclusters were identified.

SHANK2 is a scaffolding protein in the postsynaptic density and may play a role in regulating mGluR activity. One proposed role of Shank proteins is to couple postsynaptic density to the endocytic zone, which recycles mGluR5 [25]. Triple knockdown of SHANK1/2/3 with concurrent mGluR5 agonism led to decreased downstream responses and lower spine mGluR5 levels, which as discussed earlier would decrease NMDAR levels. Confirming this, SHANK3 knockdown reduced NMDAR activity [26]. However, SHANK2 dysfunction has primarily been implicated in autism spectrum disorder and autistic-like social behavior - which may connect to the role of poor social behavior in the psychopathogenesis of depression - which is improved in mice by an NMDAR agonist that normalizes the hippocampal NMDA/AMPA ratio from a reduced value caused by SHANK2 knockout [27]. SHANK2 knockout mice also had lower hippocampal plasticity. Further complicating the role of SHANK2, a more recent study shows consistent increased hippocampal plasticity in SHANK2 knockout mice, though the knockout was achieved with exon 7 deletion (as opposed to exon 6 and 7 deletion in Won et al.) and NMDA/AMPA ratios were inconsistent [28]. SHANK2 knockout localized to Purkinje cells in mice increased repetitive and anxious behavior and impaired social behavior, probably due to decreased excitatory synapse activity brought about by the knockout [29, 30]. Deletion of exon 24 induced anhedonia and manic and reward-seeking behavior in mice that were treated with mood stabilizers in addition to social impairment [31]. Consistent with Won et al., a decreased NMDA/AMPA ratio was also observed, possibly due to an increase in NMDAR NR2A and NR2B (which is coded from GRIN2B) subunit levels. Thus, different SHANK2 mutations may have varying roles in multiple neuropsychiatric disorders, which may be an area of future research.

This does raise a question about the effects of ketamine on social behavior, and indeed ketamine does induce social-withdrawal in mice [32], which is reversed by a 5-HT7 agonist and memantine [33], which is also an NMDAR antagonist and further complicates the role of NMDARs in social behavior. No firm conclusions can be made on the effect of ketamine on social behavior on humans from animal model studies, but this does open an area for future research.

GRIA genes code for AMPAR subunits.

MAPK and MAPKK genes code for components of the ERK signaling pathway, a downstream target of BDNF that leads to protein synthesis and induces inflammation as part of the stress response [34]. This pathway seems to be essential for R-ketamine's antidepressant effects, as opposed to S-ketamine which requires mTORC1 signaling [35, 36], as well as other traditional antidepressants [37]. Not only does inhibiting MAPK prevent antidepressant effects, but it also induces depressive symptoms, suggesting it has a role in the pathogenesis of depression. MAPKs are also involved in synaptic plasticity and neuroinflammation [38, 39]. The p38 MAPK-MK2 complex induces neuroinflammation and the release of proinflammatory cytokines. Activation of 
NMDARs causes p38 MAPK-mediated internalization of certain AMPARs, which underlies long-term depression [40], and AMPAR downregulation caused by NMDAR stimulation may be a mechanism for the pathogenesis of depression consistent with the disinhibition hypothesis. Consistent with this, ketamine reduced hippocampal p38 MAPK levels [36]. ERK1/p44 MAPK levels were also increased with ketamine treatment, which upregulates certain AMAPARs [40], however ERK2/p42 MAPK also upregulates AMPARs but was decreased after ketamine treatment.

CALM1 is differentially expressed in depressed patients and is involved in dopamine signaling [41]. CaMK2 is activated by NMDAR-mediated calcium intake, which then activates Ras complexes which then activates MAPK signaling that upregulates surface AMPAR levels [40].

KCJN6 may play a role in rumination [42], which is a classic psychopathogenetic mechanism of depression.

$\mathrm{NFkB}$ is a transcription factor and a downstream target of PI3K-Akt signaling, and genes coding for NFkB subunits have been implicated in hippocampal synaptic plasticity. Knockout of NFKB1 (the p50 subunit) impaired hippocampal neurogenesis and cognition in mice [43]. On the other hand, chronic IKK-mediated activation of NFkB resulted in inflammation, neurodegeneration, and reduced BDNF levels in the hippocampus which was treated with deactivation of NFkB, which may suggest a therapeutic effect from the activation of NFKBI, including NFKBIB, and other agents inhibiting NFkB activity. This is consistent with the psychopathogensis of depression as a result of chronic stress. Modulators of NFkB signaling have promise as novel antidepressants. The gabapentinoids pregabalin and gabapentin promote hippocampal neurogenesis and prevent depressive symptoms through an NFkB-dependent mechanism [44]. L-acetylcarnitine (LAC) is also a therapeutic of interest that also interacts with NFkB. In rats, LAC had antidepressant effects within days and lasted for 2 weeks after withdrawal [45]. Depressed rats had lower prefrontal and hippocampal BDNF levels and lower depolarization-evoked glutamate released, which were both treated with LAC. LAC levels are also lower in depressed patients [46]. A meta-analysis in humans found LAC to be a significantly effective monotherapy for depression treatment and even had fewer adverse effects than traditional antidepressants [47]. The mechanism underlying LAC is complex. LAC acetylates NFkB p65, which then promotes transcription of mGluR2 receptors [46, 48]. mGluR2 receptors have been observed to be upregulated, and this is prevented with NFkB inhibition [46]. Although LAC does appear to be well-tolerated, LAC's therapeutic effects are probably due to acute NFkB positive modulation, since chronic NFkB activation promoted depressive symptoms as discussed before; the effects of LAC treatment over a longer period should be further studied. In addition, upregulation of mGluR2 would cause depressive symptoms according to the disinhibition hypothesis. Previous studies have shown that elevated prefrontal mGluR2 levels are a characteristic of depressed patients [49] - which contrasts with Nasca et al., which observed downregulated prefrontal mGluR2 in depressed rats - and mGluR2 antagonism has 
antidepressant effects $[50,51]$. It is possible that LAC's antidepressant effects occur through another mechanism, and its basic mechanism and its clinical effects are areas of further research.

SLC1A2 is the glutamate transporter responsible for the majority of glutamate reuptake [52].

CACNA1C is associated with several psychiatric disorders, including bipolar disorder, depression, and schizophrenia. Complete CACNA1C knockout impaired neurogenesis, but knockdown and a heterozygous genotype had antidepressant effects [53]. A CACNA1C SNP predicts the development of depression after threatening life events [54]. Voltage-gated calcium channels in general may be associated with psychiatric disorders [55,56].

Protein-Drug Interaction Network 
The list of candidate genes was put into NetworkAnalyst to create a network of protein-drug interactions using the DrugBank database. The largest subnetwork was visualized in Cytoscape.

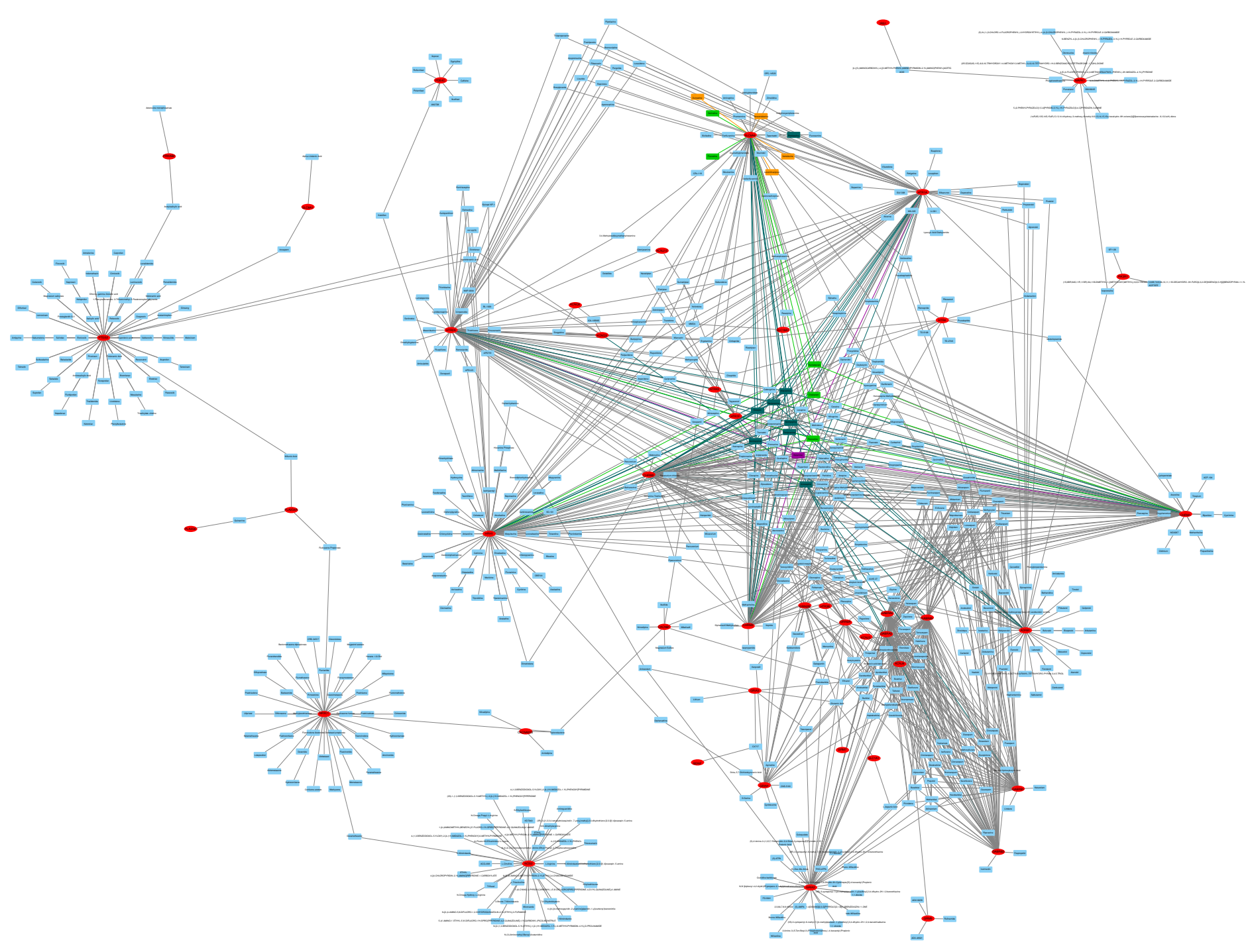

Key:

Red nodes - Candidate genes

Light blue nodes - Drugs

Purple node \& edges- Ketamine

Green nodes \& edges- SSRIs 
Orange nodes \& edges - SNRIs

Dark blue node \& edges - Tricyclics

No MAOIs were found.

Note how traditional antidepressants act on proteins of multiple pathways, not just monoaminergic systems. These interactions show other potential mechanisms that may contribute to these drugs' antidepressant effects. They also provide evidence that the products of the candidate genes are possibly implicated in the pathophysiology of depression.

Quite nicely and without intention, ketamine is at the center of the network. Though ketamine is hypothesized to act primarily on the glutamatergic system to produce antidepressant effects, its mechanism of action may involve other systems as well, including the serotonergic system [57].

Other smaller subnetworks are shown below.

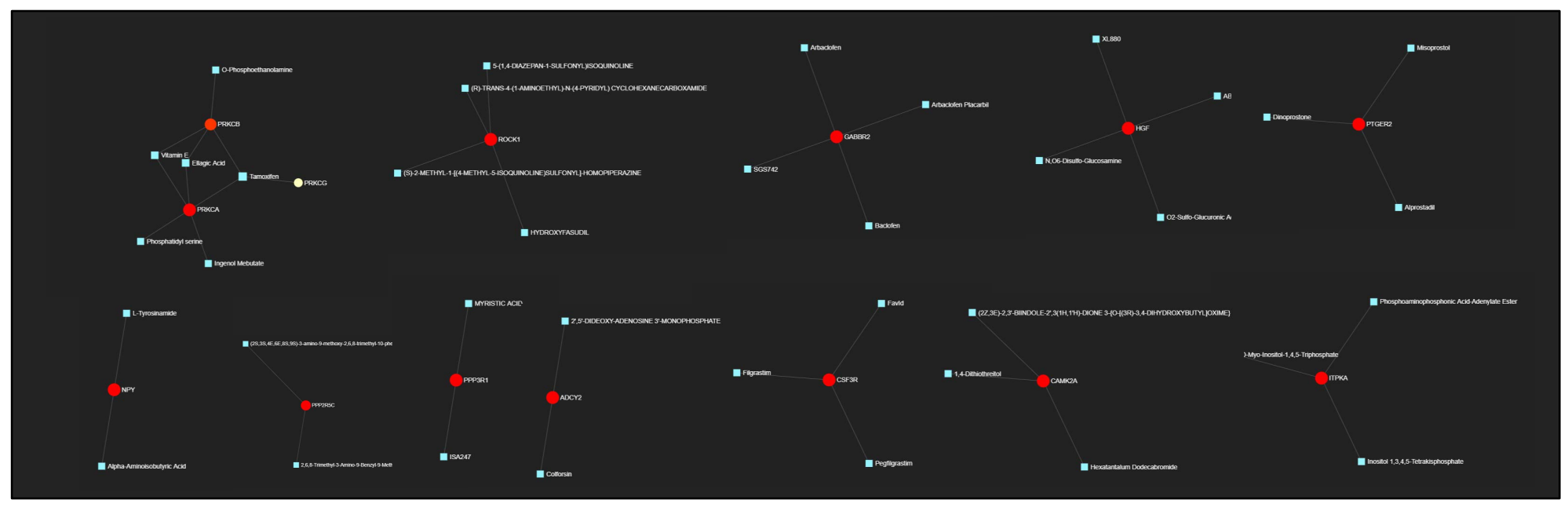

\section{Enrichment Analysis}

\section{Functional Annotation Clustering}

The genes identified from Network 1 and their isoforms are

$\begin{array}{lllllllllllllllllllll}\text { SHANK1 } & \text { SHANK2 } & \text { GRIA2 } & \text { GRIA3 } & \text { GRIA4 } & \text { MAPKAPK2 } & \text { MAPKAPK3 } & \text { MAP2K2 } & \text { MAP3K14 } & \text { MAPK3 } & \text { MAP3K1 } & \text { MAPK8 } & \text { MAPK9 } & \text { MAPK13 } & \text { MAPK10 } & \text { MAPK3K4 } \\ \text { MAPKAPK5 } & \text { MAP3K5 } & \text { MAP3K7 } & \text { MAP2K1 } & \text { MAP2K6 } & \text { MAPK1 } & \text { MAPK14 } & \text { CALM1 } & \text { CALM3 } & \text { CALM2 } & \text { CAMK2G } & \text { CAMKK2 } & \text { CAMK1 } & \text { CAMKK1 } & \text { CAMK1D } & \text { CAMK4 } \\ \text { CAMK1G } & \text { CAMK2B } & \text { CAMK2D } & \text { CAMK2A } & \text { KCNJ5 } & \text { KCNJ3 } & \text { KCNJ9 } & \text { KCNJ6 } & \text { KCNJ12 } & \text { KCNJ4 } & \text { CACNA1C } & \text { CACNB1 } & \text { CACNB2 } & \text { CACNG2 } & \text { CACNB3 } & \text { CACNA1A } \\ \text { CACNA1S } & \text { CACNA2D1 } & \text { CACNG1 } & \text { CACNA1E } & \text { CACNA2D2 } & \text { CACNA1B } & \text { CACNA1F } & \text { CACNA1D } & \text { CACNA2D3 NFKB2 } & \text { NFKBIB } & \text { NFKB1 } & \text { NFKBIA } & \text { SLC1A2 } & & \end{array}$


The gene list above was combined with the candidate gene list. This combined gene list was run through DAVID for functional annotation clustering, and the resulting clusters are shown in the table below. 


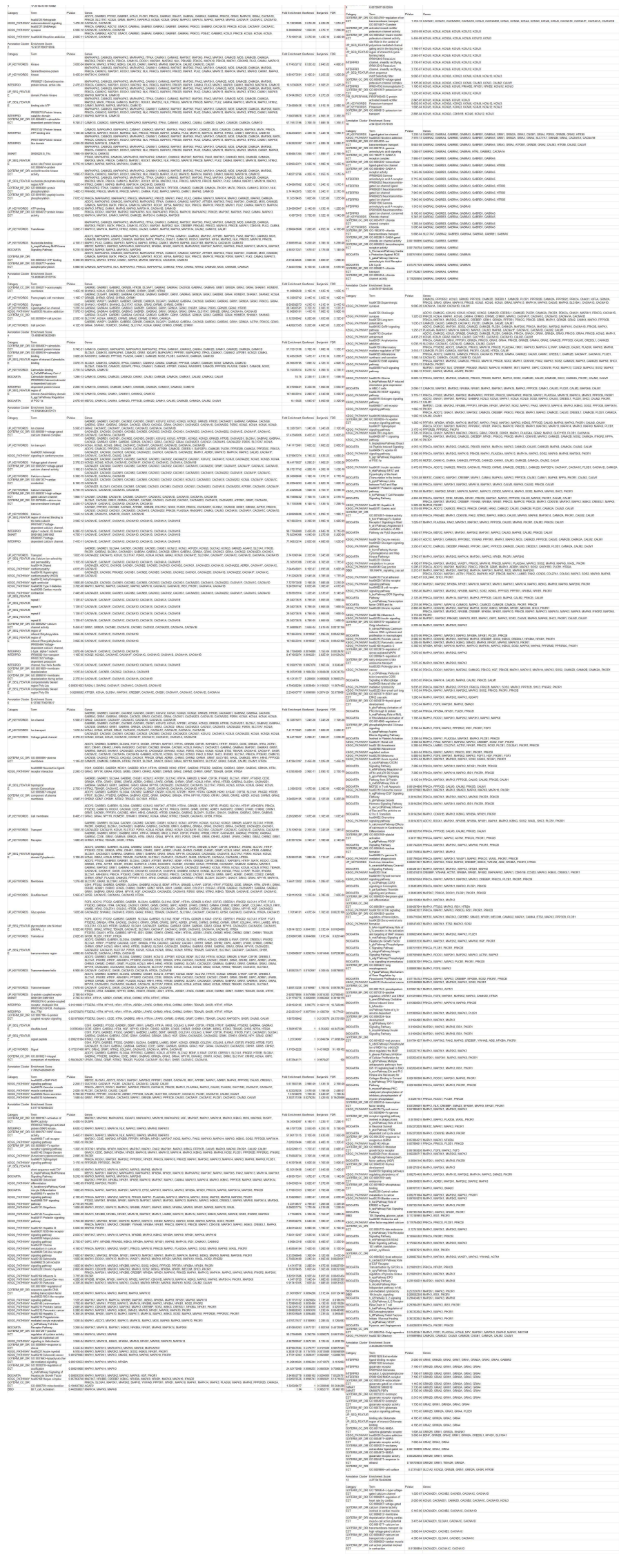

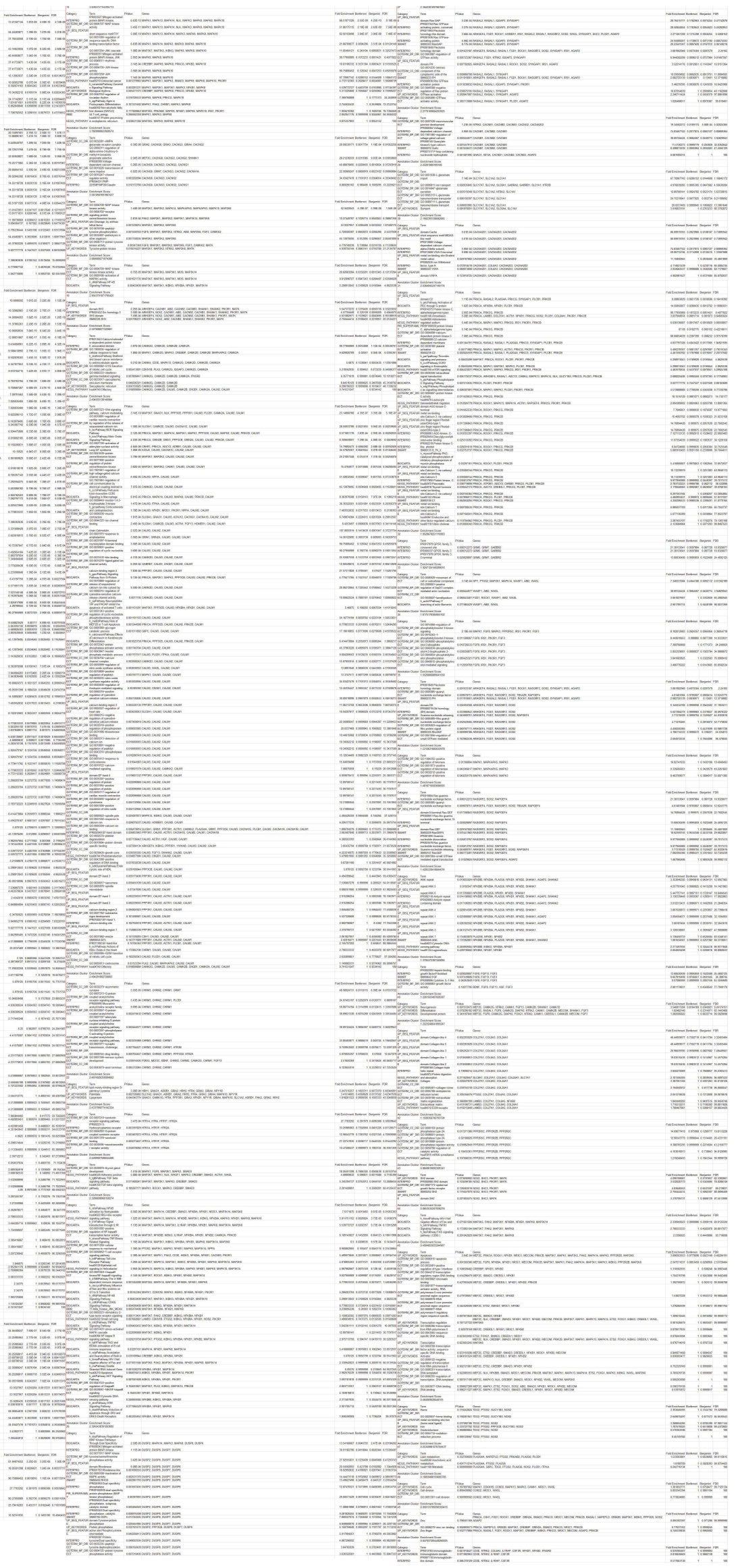


Several of these clusters have clear themes and highlight interesting molecular interactions and properties. The highest ranked cluster contains the following systems.

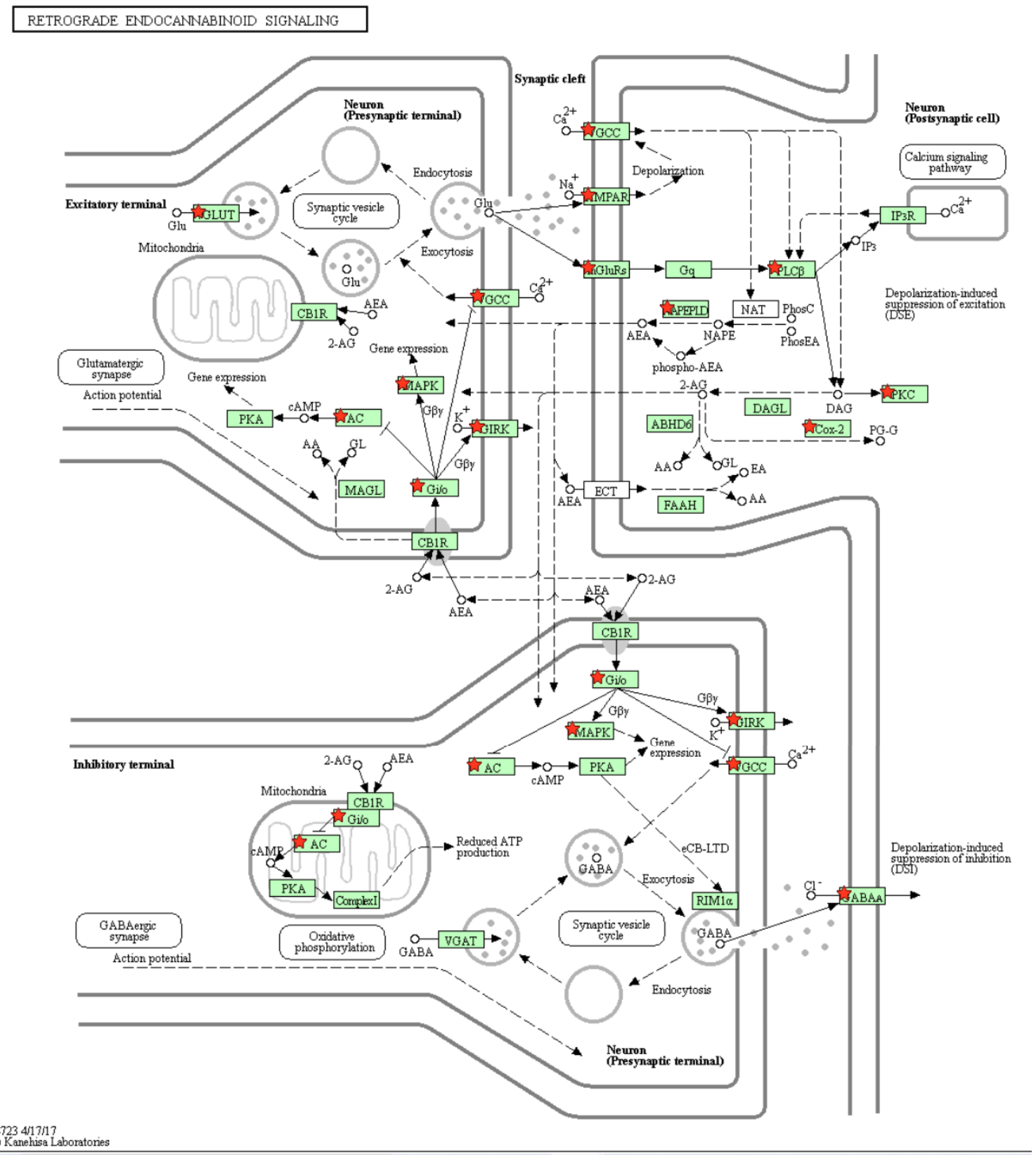


GABAERGIC SYNAPSE

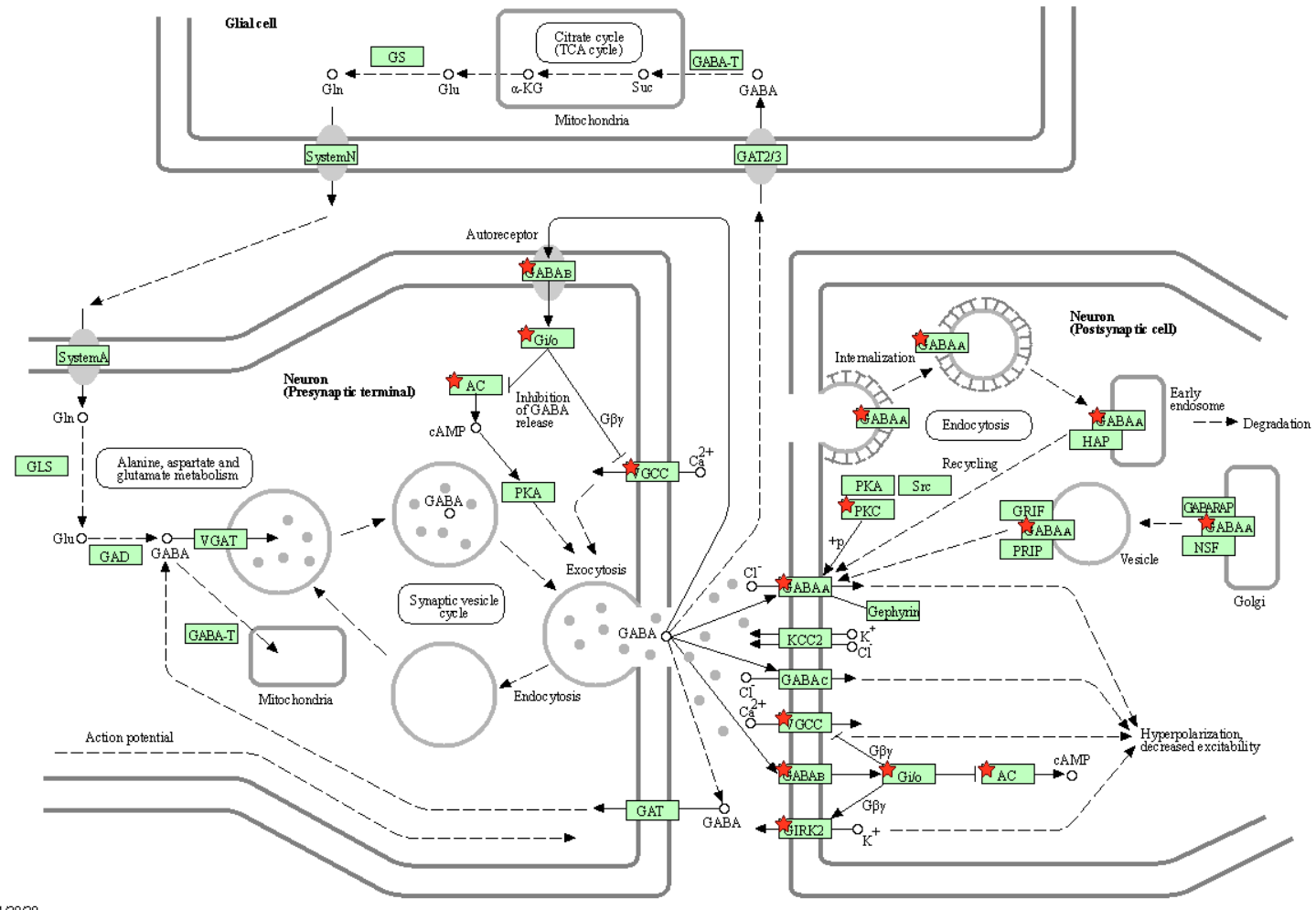

04227120200
(c) Kanehisa Laboratories

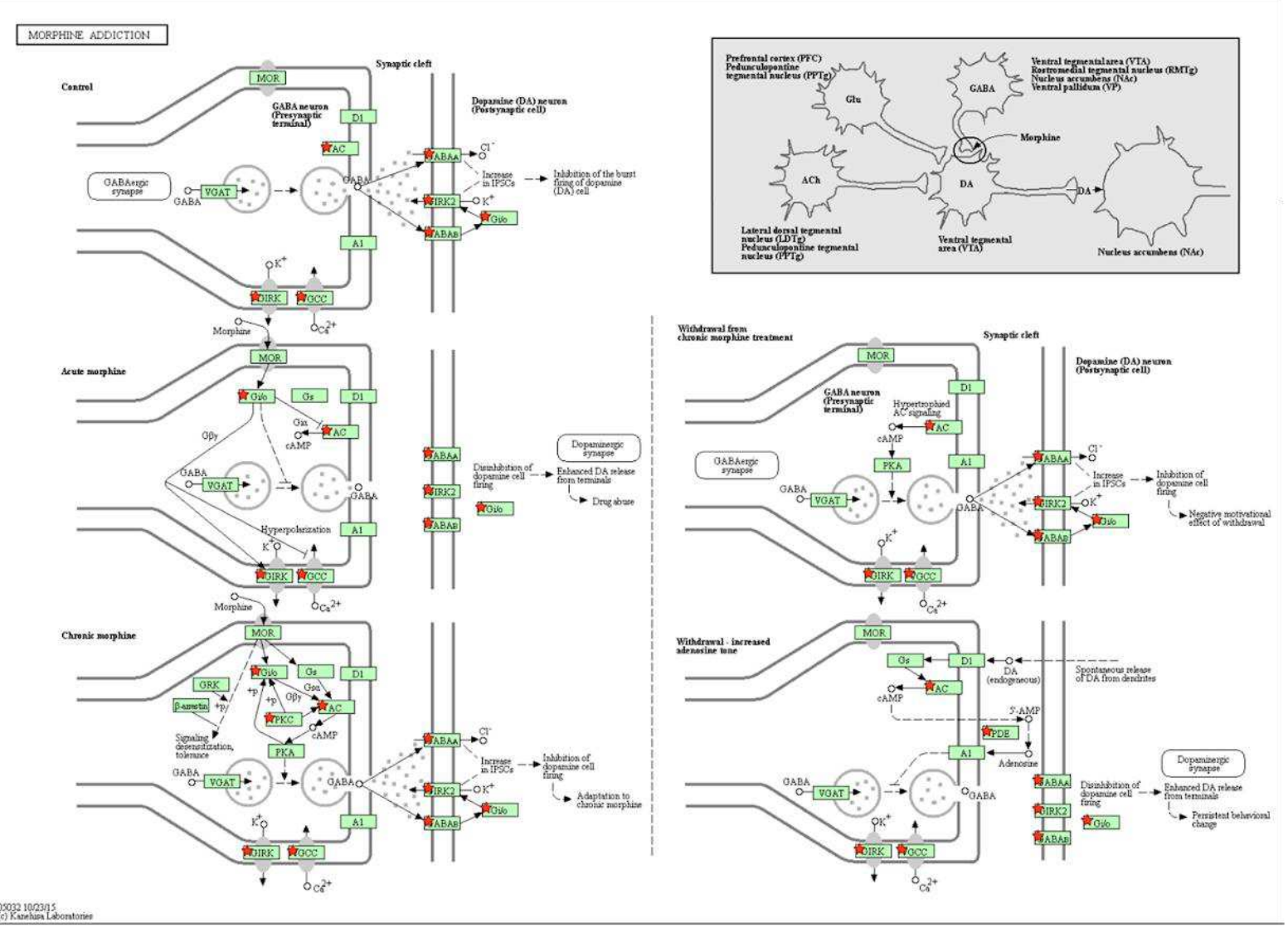


As previously discussed, GABAergnic neurons are implicated through the disinhibition hypothesis. Some other methods of reducing GABA release are inhibiting CACNA1A/B (labeled VGCC in the picture) or activating GABBR1/2 autoreceptors (labeled GABAB in the picture).

Endocannabinoids released by a local increase in calcium in postsynaptic dendritic spines inhibit further release of GABA and glutamate from the presynaptic neuron by binding to CB1 receptors. The endocannabinoid system is highly expressed in the hippocampus, a brain region implicated in depression, and is involved in the stress response [58]. CB1 receptors are present on both GABAergic and glutamatergic neurons, and CB1 receptor activation can lead to less release of both types of neurotransmitters downstream through depolarization-induced inhibition of excitation (DSE) and inhibition (DSI). According to the disinhibition hypothesis, this may produce conflicting effects with regards to depression treatment. High-affinity CB1R antagonists and agonists - since DSE and DSI are transient events - are both worth investigating for therapeutic effects, especially if they can selectively target different neuron types. Endocannabinoids may also play various roles in the synaptic plasticity of various brain regions [59].

Although morphine addiction may not appear directly relevant to depression, this pathway provides an interesting insight into the regulation of dopaminergic neurons with GABA. Additionally, acute morphine produces a similar effect as ketamine by inhibiting GABA receptors, which increases dopamine signaling for morphine - which may also occur with ketamine. This may also partially explain the potential for ketamine to become addictive, albeit to a lesser extent than morphine. Tianeptine, an atypical depressant, is a mu-opioid receptor (labeled MOR on the picture) agonist, similar to morphine. Interestingly, the mu-opioid receptor antagonist naltrexone has been shown to lessen the antidepressant effects of ketamine [60]. All of this suggests that the opioid system is involved in the pathophysiology of depression and the mechanism of action of ketamine. Buprenorphine, a partial mu-receptor agonist, has been shown to rapidly treat suicidal ideation in a randomized control trial [61]. Less potent opioids like buprenorphine in a controlled setting may have use as a last-line option for severe treatmentresistant depression. Regardless, the opioid system has potential as a novel target for depression treatment.

Clusters 8 and 11 have a theme of the immune response, and cluster 11 also includes neurotransmitter systems. T-cell signaling is also a reoccurring theme. 


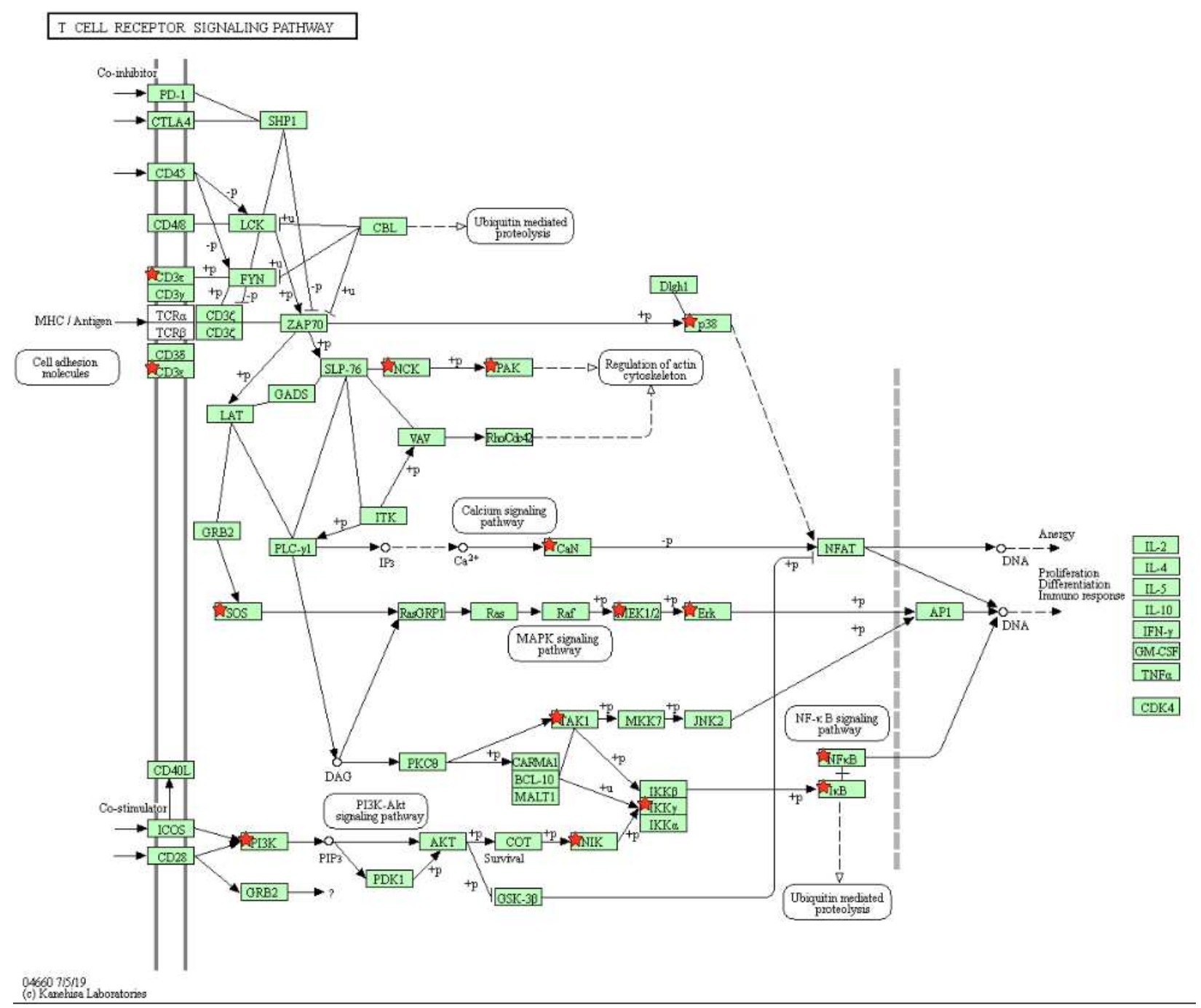

Several IL2 related functional annotations are in cluster 11, although they do not meet the threshold for statistical significance. IL2 is an anti-inflammatory cytokine, and it induces ITK which dephosphorylates the transcription factor that leads to the immune response, including the release of proinflammatory cytokines and TNF. IL2 may be a novel therapeutic that reduces the release of proinflammatory cytokines, particularly IL 17 from Th17 cells, and by stimulating T regulator cells that control inflammation [62].

Cocaine addiction is in cluster 12 . While cocaine is obviously not a practical therapeutic agent, the involved pathways reveal some interesting molecular interactions. 


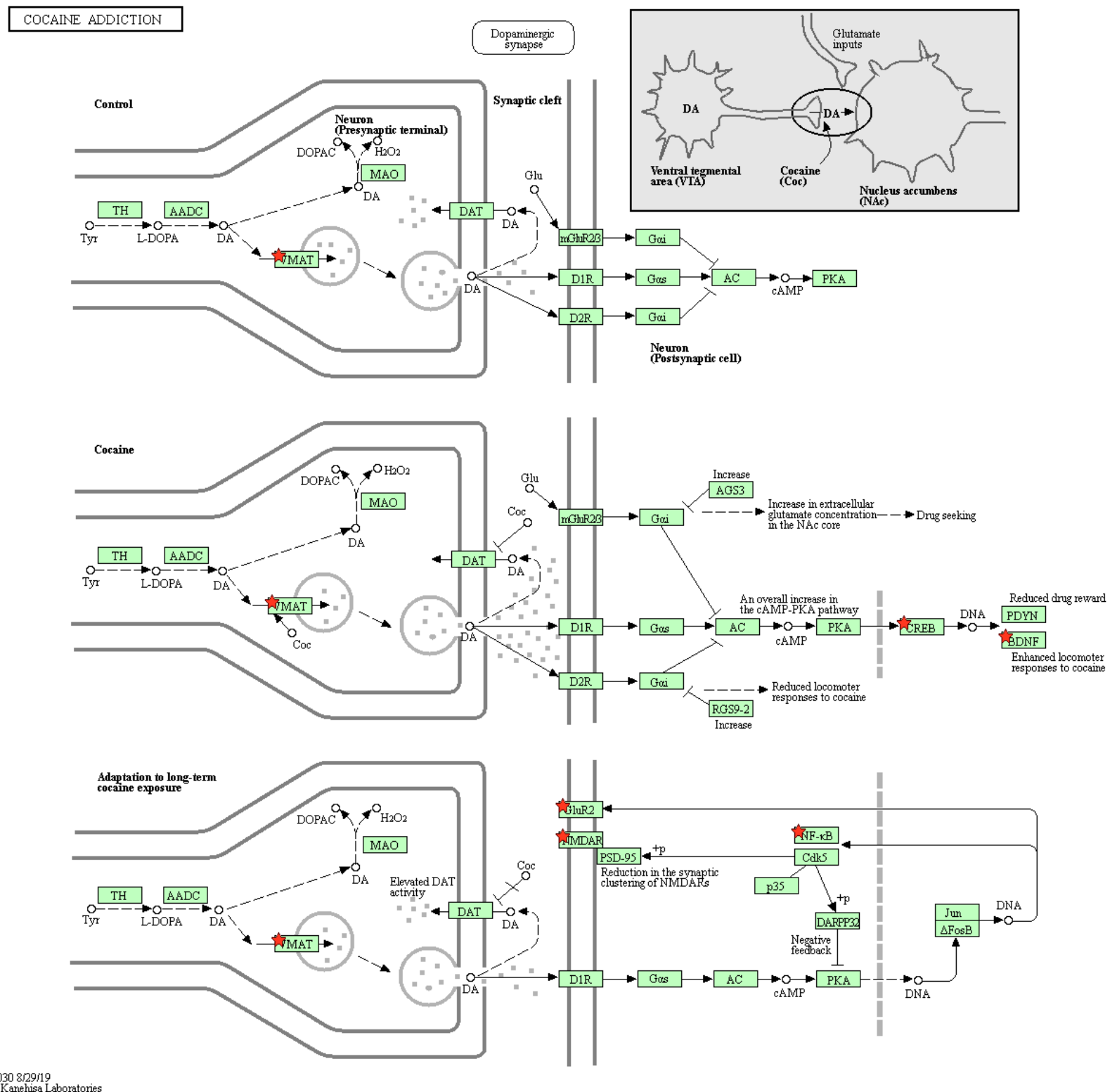

050308292119
(c) Kanehisa Laboratories

In contrast to the hippocampus, the NAc of depressed patients is hypertrophic and has increased plasticity, which seems to be reversed by ketamine [63]. Stress increases VTA mesolimbic signaling which was treated with fluoxetine [64], thus BDNF release in the NAc is also increased and explains the increased plasticity. Ketamine reduces proBDNF - the precursor to BDNF levels in the NAc (in contrast to the hippocampus, where it is increased) [36], which may explain ketamine's therapeutic mechanism in the NAc. IKK levels were increased in the NAc, which mediated increased plasticity by increasing spine formation [66]. Depressive symptoms seem to be a result of increased plasticity due to BDNF-TrkB signaling rather than mesolimbic dopamine signaling in and of itself [65]. 
Exposure to chronic social stress resulted in increased cocaine self-administration in rats [120, 121]. Social defeat that caused cocaine-seeking behavior also led to increased GluR1 AMPAR subunit levels, indicative of increased plasticity, and the NMDAR antagonist dizocilpine reduced cocaine self-administration after chronic social defeat stress. However, not all of the data reached a statistically significant p-value. From a cognitive-behavioral perspective, reducing maladaptive reward-seeking behavior in response to stress may also contribute to ketamine's antidepressant effects as an NMDAR antagonist.

From the diagram, activation of mGlur $2 / 3$ results in less production of BDNF in the NAc. However with regards to reducing depressive symptoms, activating mGlur $2 / 3$ would produce theoretically conflicting effects in glutamatergic synapses. DRD1 inhibition and DRD2 activation would also decrease BDNF production in this context.

Clusters 3 and 10 contain nicotine addiction. This pathway shows another way that GABAergic and glutamatergic neurons are regulated, through nicotinic acetylcholine receptor (nAChR).

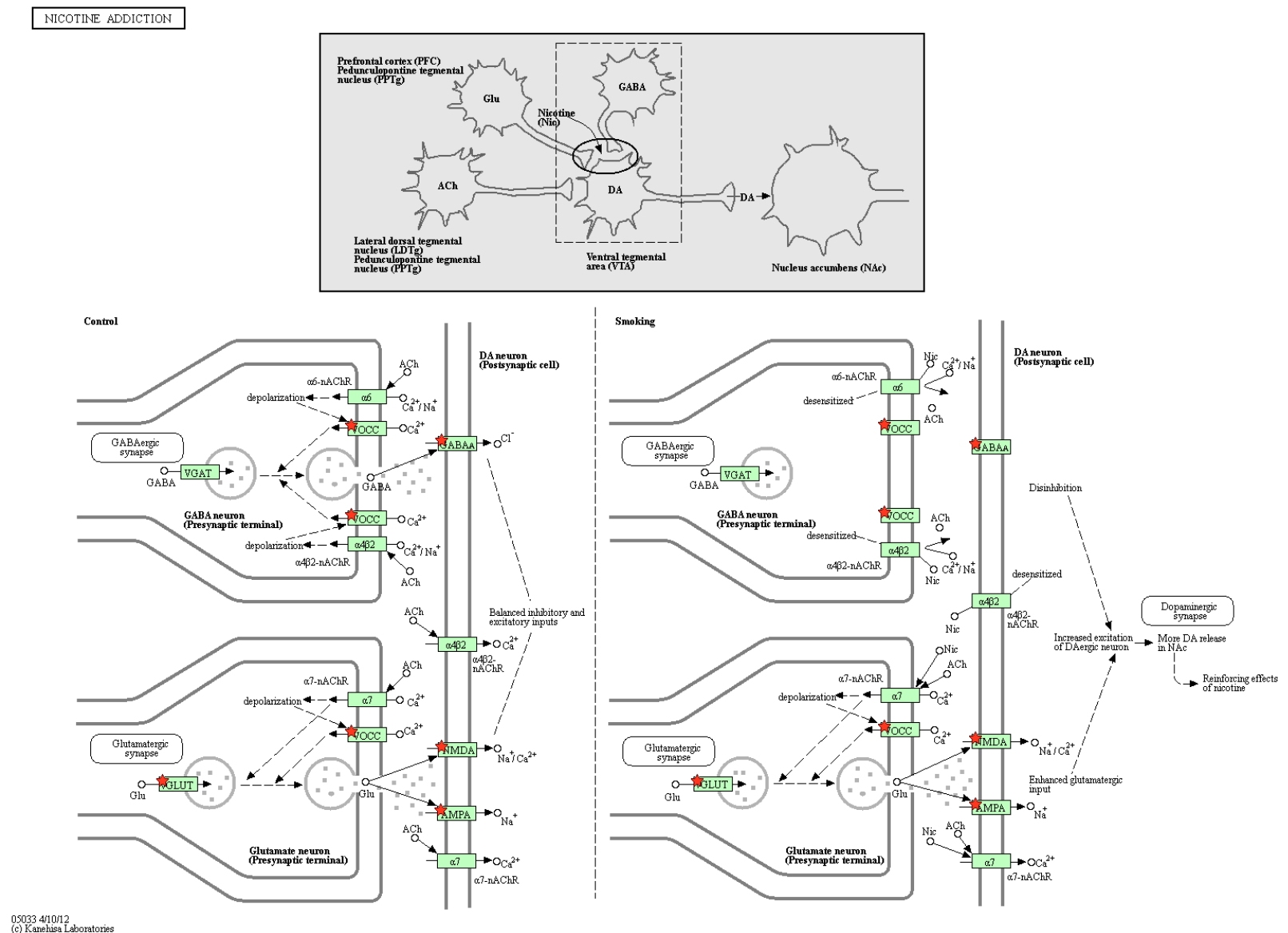

A cholinergic hypothesis of depression is not new and supported by many lines of evidence [67]. It was developed when acetylcholinesterase inhibitors were observed to induce depressive symptoms [67, 68]. 
Consistent with the psychopathogenesis of depression, acute changes in acetylcholine levels due to acute stress can produce adaptive behaviors, but chronic changes can be responsible for maladaptive behaviors [70]. Interestingly, depressive symptoms in mice induced by an acetylcholinesterase inhibitor could even be reversed by nAChR antagonists and fluoxetine, which also increased acetylcholinesterase activity [71]. Also, increased acetylcholine signaling in the hippocampus particularly seems to contribute to depressive symptoms. Alpha-7 receptor agonists resulted in increased glutamate release and induced long-term potentiation in the hippocampus [72]. Clinical studies have shown that transdermal nicotine has antidepressant effects, notably also in older patients with late-life depression which is characterized by poor antidepressant response [73, 74], which is possibly due to the chronic desensitization of alpha-4 beta-2 nAChRs. Bupropion, a drug that supports smoking cessation, also functions as an antidepressant. It is an antagonist of alpha-4 beta- 2 nAChRs [75], which possibly contributes to its antidepressant effects by reducing GABA inhibition of dopaminergic neurons. In postmortem subjects, beta- 2 subunits were significantly less available in depressed subjects - possibly due to higher levels of acetylcholine - with the availability of the receptors significantly correlating with severity of depression [69].

However, a model of alpha- 4 beta- 2 nAChR stimulation inducing depression completely contradicts the previous NAc plasticity model. Decreasing alpha-4 beta- 2 activity, whether through antagonism or desensitization, reduces inhibitory neuron activity and increases dopamine release, which increases NAc plasticity downstream. However, there is evidence that alpha7 nAChR stimulation induces depressive symptoms [76] and cytisine, a selective alpha-4 beta-2 partial agonist, which is consistent with the NAc plasticity model [77]. However, there is contradictory evidence that alpha7 nAChR knockout induced depressive symptoms and increased NAc synaptogenesis and BDNF levels [78]. It is clear that this system is complex and has some involvement in the pathophysiology of depression, but more research is needed before a consistent model can be created. Alpha-7 receptors are also present on macrophages, and when triggered inhibit the release of proinflammatory cytokines [79].

Addictive drugs, including morphine, nicotine, and cocaine decrease GABA inhibition of dopamine [80]. Acute stress also appears to decrease GABA inhibition through the glucocorticoid system, which is consistent with the NAc plasticity model. Annotations involving GABA are also clustered with nicotine addiction.

Consistent with the NAc plasticity model, chronic stress elevates the VTA AMPAR/NMDAR ratio and alpha-7 activation increases susceptibility to social stress [81]. In addition, chronic nicotine decreased subsequence VTA dopamine signaling in response to acute IV nicotine. This supports chronic nicotine patches as a treatment, if this result is due to globally decreased VTA dopamine signaling - which would lead to decreased NAc plasticity downstream. However, chronic nicotine also led to increased social avoidance. 
Benzodiazepine receptor activity is also in the same cluster as nicotine addiction, which might also suggest another connection [82].

There are other clusters with consistent themes, which may or may not be involved in the pathophysiology of depression, and they were identified manually.

Clusters 4, 5, 20, and 30 involve calcium signaling.

Cluster 23 involves serotonin.

Cluster 25 involves the immune system.

Cluster 26 involves TGF beta.

Cluster 36 involves telomere regulation. Depressed individuals appear to have shorter telomere length [83], and telomere length predicts SSRI response [84, 85].

Cluster 37 involves guanine nucleotide exchange factor.

Cluster 41 involves the extracellular matrix.

Cluster 45 involves DNA regulation.

\section{$\underline{\text { Set Intersection }}$}

Every gene from the unfiltered PPI network from the end of part 2.II was put into DAVID and annotated with Gene Ontology terms. A python script was used to find certain keywords and genes associated with those keywords. In the table below, genes are grouped into sets based on which theory of depression they fall under, with the keyword used in the second row. 


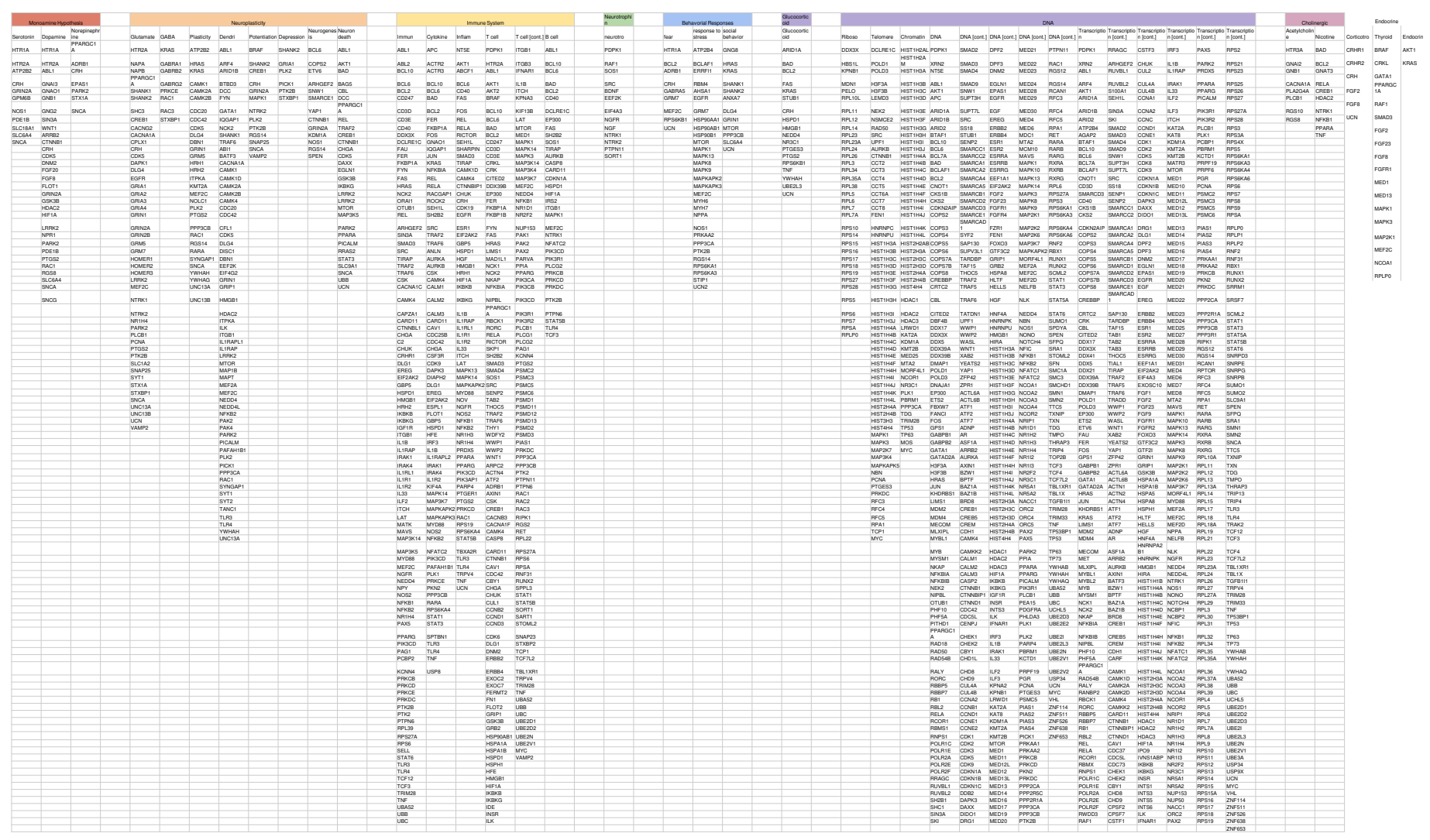

Using UpSetR, the intersection of the sets was plotted, and intersections were ordered by increasing intersection degree. Genes belonging to multiple sets are functionally linked to multiple theories of depression and are the most interesting.

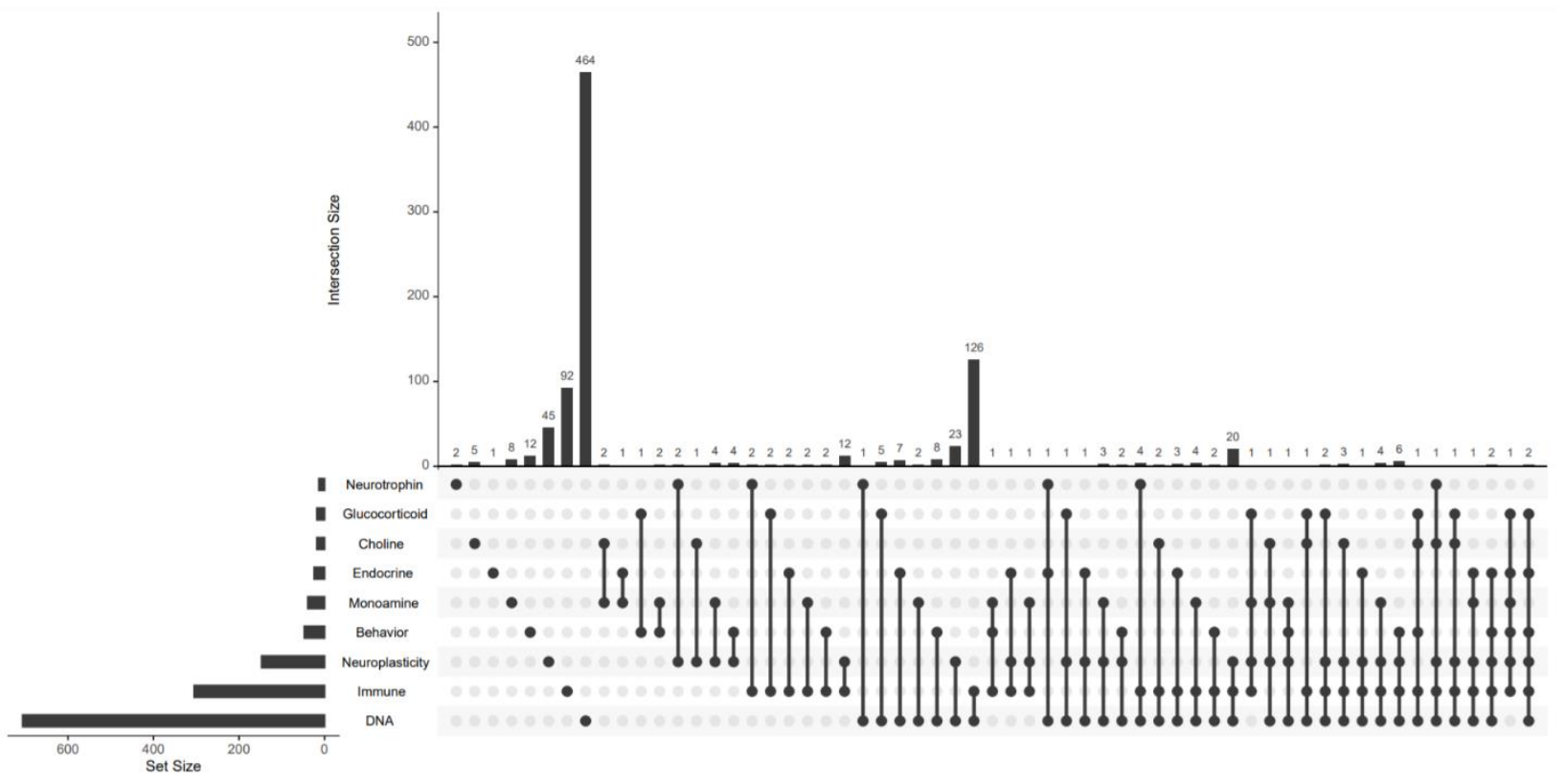




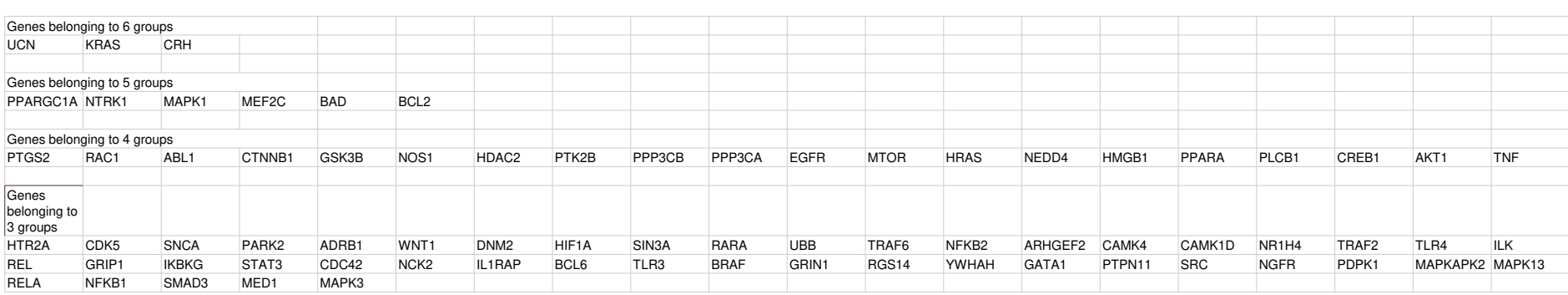

Table 3

For brevity, an overview will only be done on the genes with evidence supporting a connection to depression from the 6,5 , and 4-degree intersections.

Urocortin (UCN) is a high-level regulator of the stress response and within the same family as $\mathrm{CRH}$. It promotes anxious behavior and decreases appetite [86], which is a symptom of depression, though its wide-reaching regulatory roles makes it an unlikely practical therapeutic target.

PGC-1 alpha (PPARGC1A) regulates mitochondrial biogenesis and gene expression. Activation of PGC-1 alpha through exercise redirects the kynurenine pathway towards the production of kynurenic acid, which is an NMDA antagonist [87]. Downregulated PGC-1 alpha results in oxidative stress, inflammation, and NFkB activation, and TNF decreases PGC-1 alpha expression [88].

TrkA (NTRK1) is the receptor for nerve growth factor and related to TrkB, the receptor for BDNF. The tricyclic antidepressant amitriptyline is a TrkA/B agonist [89].

$\mathrm{MEF} 2 \mathrm{C}$ is a transcription factor. In mice, increased activity results in increased dendritic spine density and complexity in several brain regions, including the hippocampus [90].

In mice, decreasing NAc RAC1 expression induces social defeat behavior and anhedonia, which is reversed by upregulation [91].

ABL1 is a proto-oncogene for gastric cancer. Depression-induced oxidative stress exacerbates the prognosis of cancer patients through ABL1-involved pathways [92].

Beta-catenin (CTNNB1) is a key player in the canonical Wnt pathway, and WNT1 is a ligand initiating the pathway. Beta-catenin promotes transcription of certain genes, and direct nucleic beta-catenin insertion into the NAc promotes stress-resilience and produces antidepressant effects [93]. D2 dopamine receptor activation promotes beta-catenin mediated transcription [94]. In the hippocampus, canonical Wnt signaling has a positive role in neurogenesis [95]. Glutamate activation of NMDARs results in calpain-dependent cleavage of beta-catenin in the hippocampus [96], and cleaved beta-catenin resulted in greater transcription activity, which is paradoxical considering ketamine's antidepressant effects and mechanism as an NMDAR antagonist. However, the study was conducted with a focus on cancer rather than on neuronal cells, and 
extranuclear interactions of beta-catenin may also be present [97]. Overall, it appears that increasing beta-catenin signaling produces antidepressant effects, and Wnt ligands may produce therapeutic effects.

GSK-3b is also involved in canonical Wnt signaling. GSK-3b ubiquitinates beta-catenin for proteolysis, and cleaved beta-catenin is resistant to this degradation [96]. Consistent with the hypothesis of beta-catenin having therapeutic effects, overactive GSK-3b is associated with depressive symptoms [98]. Also, GSK-3b mediates maladaptive NAc plasticity [99], and knockdown prevents depressive symptoms. GSK-3b is also inhibited lithium, and ketamine, which is necessary for its antidepressant effects [18]. Akt signaling leads to mTOR-mediated inhibition of GSK-3b, which may explain the role of mTORC1 in the pathophysiology of depression. GSK-3b inhibitors may be a novel antidepressant.

NOS1 codes for nitric oxide synthase 1. NO modulates norepinephrine, serotonin, dopamine, and glutamate, and inhibition of NOS prevented neurotoxicity resulting from NMDA agonism [100]. Many conventional and atypical antidepressants interact with NO pathways.

HDAC2 codes for histone deacetylase 2. Depression is associated with increased acetylation of histone H3 and decreased HDAC2 expression in the NAc, and HDAC2 also mediates hippocampal plasticity [101]. Direct insertion of HDAC has antidepressant effects and reverses the effects of chronic defeat stress. Interestingly, the study also implicates genes involved in the effects of cocaine, as previously enriched.

Patients with lung cancer with EGFR mutations had higher TNF-alpha levels, which is normally associated with depression, but paradoxically tended to have lower depression severity [102].

Maternal immune activation during pregnancy leads to inflammation, which results in decreased NEDD4 activity that leads to decreased neurogenesis and synapse formation and is a risk factor for depression [103].

HMGB1 is a chromatin protein that aids in transcription. Upregulated HMGB1 is associated with increased presence and activity of kynurenine pathway enzymes [104].

PPAR-alpha (PPARA) is a transcription factor. PEA, an endogenous PPAR-alpha agonist, has

antidepressant effects $[105,106]$. PPARs may also be involved in the endocannabinoid system [107].

\section{Conclusion}

The purpose of this was to identify novel systems underlying the pathophysiology of depression as research directions and potential therapeutic targets. First, starting representative genes were selected from the major current paradigms of depression: the serotonin hypothesis (and kynurenine pathway), glutamate hypothesis, neuroplasticity, inflammation, the HPA axis, and the stress response. Using publicly available microarray datasets on Allen Brain Atlas, gene 
correlates were identified and filtered for genes related to depression using DAVID to make a gene candidate list. Creating a protein interaction network from the starting genes, subnetworks originating from the glucocorticoid receptor coded by NR3C1 were identified based on high interconnectivity. These subnetworks had themes of histones, the COP9 signalosome, SWI/SNF chromatin remodeling complexes, the estrogen receptor, and ribosomes. A drug-protein interaction network was created to identify potential therapeutic agents for further investigation and to find interactions between currently established antidepressants with candidate genes. Ketamine was at the center of the network and connected to many of the candidate genes, thereby validating this methodology. Creating a protein interaction network with the candidate genes and organizing for highly interconnected subclusters, SHANK2, GRIA2/3/4, MAPK \& MAPKK genes, CALM \& CAMK genes, KCJN6, CACN genes, NFKB genes, and SLC1A2 were identified as genes of interest. The candidate genes and the genes in interesting clusters identified from the network were enriched with DAVID. The most notable enrichment clusters had themes of GABAergic regulation, endocannabinoid signaling, opioid signaling, cholinergic signaling, and T-cell and antibody signaling. Potential pathogenesis and therapeutic mechanisms involving these systems were proposed based on KEGG pathway illustrations and molecular interactions. Using Gene Ontology annotations, every gene from the candidate protein interaction network was classified into groups based on current theories of depression. Genes belonging to multiple groups are highly interesting and were identified. These genes may be the subject of future research and novel paradigms.

\section{References}

1. Global, regional, and national incidence, prevalence, and years lived with disability for 354 diseases and injuries for 195 countries and territories, 1990-2017: A systematic analysis for the Global Burden of Disease Study 2017. (2018). The Lancet, 392(10159), 1789-1858. https://doi.org/10.1016/S0140-6736(18)32279-7

2. 2017 methodological summary and definitions | cbhsq data. (n.d.). https://www.samhsa.gov/data/report/2017-methodological-summary-and-definitions

3. Bansal, Y., Singh, R., Parhar, I., Kuhad, A., \& Soga, T. (2019). Quinolinic acid and nuclear factor erythroid 2-related factor 2 in depression: Role in neuroprogression. Frontiers in Pharmacology, 10. https://doi.org/10.3389/fphar.2019.00452

4. Pu, J., Liu, Y., Zhang, H., Tian, L., Gui, S., Yu, Y., Chen, X., Chen, Y., Yang, L., Ran, Y., Zhong, X., Xu, S., Song, X., Liu, L., Zheng, P., Wang, H., \& Xie, P. (2020). An integrated meta-analysis of peripheral blood metabolites and biological functions in major depressive disorder. Molecular Psychiatry, 1-12. https://doi.org/10.1038/s41380020-0645-4 
5. Bender, D. A. (2003). Niacin | physiology. In Encyclopedia of Food Sciences and Nutrition (pp. 4119-4128). Elsevier. https://doi.org/10.1016/B0-12-227055-X/00827-0

6. Gałecki, P., \& Talarowska, M. (2018). Inflammatory theory of depression. Psychiatria Polska, 52(3), 437-447. https://doi.org/10.12740/PP/76863

7. Leonard, B. E. (2010, July 31). The concept of depression as a dysfunction of the immune system. Current Immunology Reviews (Discontinued). https://www.eurekaselect.com/86538/article

8. Mandal, S., Sinha, V. K., \& Goyal, N. (2019). Efficacy of ketamine therapy in the treatment of depression. Indian Journal of Psychiatry, 61(5), 480-485. https://doi.org/10.4103/psychiatry.IndianJPsychiatry_484_18

9. Sanacora, G., Treccani, G., \& Popoli, M. (2012). Towards a glutamate hypothesis of depression. Neuropharmacology, 62(1), 63-77. https://doi.org/10.1016/j.neuropharm.2011.07.036

10. Monteggia, Lisa. M., Gideons, E., \& Kavalali, E. T. (2013). The role of eef2 kinase in rapid antidepressant action of ketamine. Biological Psychiatry, 73(12), 1199-1203. https://doi.org/10.1016/j.biopsych.2012.09.006

11. Albert, P. R. (2012). Transcriptional regulation of the 5-HT1A receptor: Implications for mental illness. Philosophical Transactions of the Royal Society B: Biological Sciences, 367(1601), 2402-2415. https://doi.org/10.1098/rstb.2011.0376

12. Zhang, C., Li, Z., Wu, Z., Chen, J., Wang, Z., Peng, D., Hong, W., Yuan, C., Wang, Z., Yu, S., Xu, Y., Xu, L., Xiao, Z., \& Fang, Y. (2014). A study of N-methyl-D-aspartate receptor gene (Grin2b) variants as predictors of treatment-resistant major depression. Psychopharmacology, 231(4), 685-693. https://doi.org/10.1007/s00213-013$\underline{3297-0}$

13. Köhler, O., Benros, M. E., Nordentoft, M., Farkouh, M. E., Iyengar, R. L., Mors, O., \& Krogh, J. (2014). Effect of anti-inflammatory treatment on depression, depressive symptoms, and adverse effects: A systematic review and meta-analysis of randomized clinical trials. JAMA Psychiatry, 71(12), 1381. https://doi.org/10.1001/jamapsychiatry.2014.1611

14. Jin, D.-Z., Xue, B., Mao, L.-M., \& Wang, J. Q. (2015). Metabotropic glutamate receptor 5 upregulates surface NMDA receptor expression in striatal neurons via CaMKII. Brain Research, 1624, 414-423. https://doi.org/10.1016/j.brainres.2015.07.053 
15. Alt, A., Nisenbaum, E. S., Bleakman, D., \& Witkin, J. M. (2006). A role for AMPA receptors in mood disorders. Biochemical Pharmacology, 71(9), 1273-1288. https://doi.org/10.1016/j.bcp.2005.12.022

16. Zanos, P., \& Gould, T. D. (2018). Mechanisms of ketamine action as an antidepressant. Molecular Psychiatry, 23(4), 801-811. https://doi.org/10.1038/mp.2017.255

17. Li, N., Lee, B., Liu, R.-J., Banasr, M., Dwyer, J. M., Iwata, M., Li, X.-Y., Aghajanian, G., \& Duman, R. S. (2010). Mtor-dependent synapse formation underlies the rapid antidepressant effects of nmda antagonists. Science, 329(5994), 959-964. https://doi.org/10.1126/science.1190287

18. Duman, R. S., \& Voleti, B. (2012). Signaling pathways underlying the pathophysiology and treatment of depression: Novel mechanisms for rapid-acting agents. Trends in Neurosciences, 35(1), 47-56. https://doi.org/10.1016/j.tins.2011.11.004

19. Abdallah, C. G., Averill, L. A., Gueorguieva, R., Goktas, S., Purohit, P., Ranganathan, M., Sherif, M., Ahn, K.-H., D’Souza, D. C., Formica, R., Southwick, S. M., Duman, R. S., Sanacora, G., \& Krystal, J. H. (2020). Modulation of the antidepressant effects of ketamine by the mTORC1 inhibitor rapamycin. Neuropsychopharmacology, 45(6), 990997. https://doi.org/10.1038/s41386-020-0644-9

20. Głombik, K., Stachowicz, A., Trojan, E., Olszanecki, R., Ślusarczyk, J., Suski, M., Chamera, K., Budziszewska, B., Lasoń, W., \& Basta-Kaim, A. (2017). Evaluation of the effectiveness of chronic antidepressant drug treatments in the hippocampal mitochondria - A proteomic study in an animal model of depression. Progress in NeuroPsychopharmacology and Biological Psychiatry, 78, 51-60. https://doi.org/10.1016/j.pnpbp.2017.05.014

21. Bielawski, T., Misiak, B., Moustafa, A., \& Frydecka, D. (2019). Epigenetic mechanisms, trauma, and psychopathology: Targeting chromatin remodeling complexes. Reviews in the Neurosciences, 30(6), 595-604. https://doi.org/10.1515/revneuro-2018-0055

22. Renthal, W., \& Nestler, E. J. (2009). Chromatin regulation in drug addiction and depression. Dialogues in Clinical Neuroscience, 11(3), 257-268.

23. Oh, Y.-S., Gao, P., Lee, K.-W., Ceglia, I., Seo, J.-S., Zhang, X., Ahn, J.-H., Chait, B. T., Patel, D. J., Kim, Y., \& Greengard, P. (2013). Smarca3, a chromatin-remodeling factor, is required for p11-dependent antidepressant action. Cell, 152(4), 831-843. https://doi.org/10.1016/j.cell.2013.01.014

24. Smagin, D. A., Kovalenko, I. L., Galyamina, A. G., Bragin, A. O., Orlov, Y. L., \& Kudryavtseva, N. N. (2016). Dysfunction in ribosomal gene expression in the 
hypothalamus and hippocampus following chronic social defeat stress in male mice as revealed by rna-seq. Neural Plasticity, 2016, 1-6. https://doi.org/10.1155/2016/3289187

25. Scheefhals, N., Catsburg, L. A. E., Westerveld, M. L., Blanpied, T. A., Hoogenraad, C. C., \& MacGillavry, H. D. (2019). Shank proteins couple the endocytic zone to the postsynaptic density to control trafficking and signaling of metabotropic glutamate receptor 5. Cell Reports, 29(2), 258-269.e8. https://doi.org/10.1016/j.celrep.2019.08.102

26. Duffney, L. J., Wei, J., Cheng, J., Liu, W., Smith, K. R., Kittler, J. T., \& Yan, Z. (2013). Shank3 deficiency induces nmda receptor hypofunction via an actin-dependent mechanism. Journal of Neuroscience, 33(40), 15767-15778. https://doi.org/10.1523/JNEUROSCI.1175-13.2013

27. Won, H., Lee, H.-R., Gee, H. Y., Mah, W., Kim, J.-I., Lee, J., Ha, S., Chung, C., Jung, E. S., Cho, Y. S., Park, S.-G., Lee, J.-S., Lee, K., Kim, D., Bae, Y. C., Kaang, B.-K., Lee, M. G., \& Kim, E. (2012). Autistic-like social behaviour in Shank2-mutant mice improved by restoring NMDA receptor function. Nature, 486(7402), 261-265. https://doi.org/10.1038/nature11208

28. Wegener, S., Buschler, A., Stempel, A. V., Kang, S. J., Lim, C.-S., Kaang, B.-K., Shoichet, S. A., Manahan-Vaughan, D., \& Schmitz, D. (2018). Defective synapse maturation and enhanced synaptic plasticity in shank2 dex7-I- mice. ENeuro, 5(3). https://doi.org/10.1523/ENEURO.0398-17.2018

29. Ha, S., Lee, D., Cho, Y. S., Chung, C., Yoo, Y.-E., Kim, J., Lee, J., Kim, W., Kim, H., Bae, Y. C., Tanaka-Yamamoto, K., \& Kim, E. (2016). Cerebellar shank2 regulates excitatory synapse density, motor coordination, and specific repetitive and anxiety-like behaviors. Journal of Neuroscience, 36(48), 12129-12143. https://doi.org/10.1523/JNEUROSCI.1849-16.2016

30. Peter, S., ten Brinke, M. M., Stedehouder, J., Reinelt, C. M., Wu, B., Zhou, H., Zhou, K., Boele, H.-J., Kushner, S. A., Lee, M. G., Schmeisser, M. J., Boeckers, T. M., Schonewille, M., Hoebeek, F. E., \& De Zeeuw, C. I. (2016). Dysfunctional cerebellar Purkinje cells contribute to autism-like behaviour in Shank2 -deficient mice. Nature Communications, 7(1), 12627. https://doi.org/10.1038/ncomms12627

31. Pappas, A. L., Bey, A. L., Wang, X., Rossi, M., Kim, Y. H., Yan, H., Porkka, F., Duffney, L. J., Phillips, S. M., Cao, X., Ding, J., Rodriguiz, R. M., Yin, H. H., Weinberg, R. J., Ji, R.-R., Wetsel, W. C., \& Jiang, Y. (2017). Deficiency of Shank2 causes manialike behavior that responds to mood stabilizers. JCI Insight, 2(20). https://doi.org/10.1172/jci.insight.92052 
32. Hołuj, M., Popik, P., \& Nikiforuk, A. (2015). Improvement of ketamine-induced social withdrawal in rats: The role of 5-HT7 receptors. Behavioural Pharmacology, 26(8), 766775. https://doi.org/10.1097/FBP.0000000000000132

33. Uribe, E., Landaeta, J., Wix, R., \& Eblen, A. (2013). Memantine reverses social withdrawal induced by ketamine in rats. Experimental Neurobiology, 22(1), 18-22. https://doi.org/10.5607/en.2013.22.1.18

34. Coulthard, L. R., White, D. E., Jones, D. L., McDermott, M. F., \& Burchill, S. A. (2009). P38mapk: Stress responses from molecular mechanisms to therapeutics. Trends in Molecular Medicine, 15(8), 369-379. https://doi.org/10.1016/j.molmed.2009.06.005

35. Zanos, P., \& Gould, T. D. (2018). Intracellular signaling pathways involved in (S)- and k(R)etamine antidepressant actions. Biological Psychiatry, 83(1), 2-4. https://doi.org/10.1016/j.biopsych.2017.10.026

36. Réus, G. Z., Vieira, F. G., Abelaira, H. M., Michels, M., Tomaz, D. B., dos Santos, M. A. B., Carlessi, A. S., Neotti, M. V., Matias, B. I., Luz, J. R., Dal-Pizzol, F., \& Quevedo, J. (2014). MAPK signaling correlates with the antidepressant effects of ketamine. Journal of Psychiatric Research, 55, 15-21. https://doi.org/10.1016/j.jpsychires.2014.04.010

37. Duman, C. H., Schlesinger, L., Kodama, M., Russell, D. S., \& Duman, R. S. (2007). A role for map kinase signaling in behavioral models of depression and antidepressant treatment. Biological Psychiatry, 61(5), 661-670. https://doi.org/10.1016/j.biopsych.2006.05.047

38. Corrêa, S. A. L., \& Eales, K. L. (2012). The role of p38 mapk and its substrates in neuronal plasticity and neurodegenerative disease. Journal of Signal Transduction, 2012, 1-12. https://doi.org/10.1155/2012/649079

39. Thomas, G. M., \& Huganir, R. L. (2004). MAPK cascade signalling and synaptic plasticity. Nature Reviews Neuroscience, 5(3), 173-183. https://doi.org/10.1038/nrn1346

40. Zhu, J. J., Qin, Y., Zhao, M., Van Aelst, L., \& Malinow, R. (2002). Ras and rap control ampa receptor trafficking during synaptic plasticity. Cell, 110(4), 443-455. https://doi.org/10.1016/S0092-8674(02)00897-8

41. Martins-de-Souza, D., Guest, P. C., Harris, L. W., Vanattou-Saifoudine, N., Webster, M. J., Rahmoune, H., \& Bahn, S. (2012). Identification of proteomic signatures associated with depression and psychotic depression in post-mortem brains from major depression patients. Translational Psychiatry, 2(3), e87-e87. https://doi.org/10.1038/tp.2012.13

42. Lazary, J., Juhasz, G., Anderson, I. M., Jacob, C. P., Nguyen, T. T., Lesch, K.-P., Reif, A., Deakin, J. F. W., \& Bagdy, G. (2011). Epistatic interaction of CREB1 and KCNJ6 on 
rumination and negative emotionality. European Neuropsychopharmacology, 21(1), 6370. https://doi.org/10.1016/j.euroneuro.2010.09.009

43. Bortolotto, V., Cuccurazzu, B., Canonico, P. L., \& Grilli, M. (2014, February 12). Nf- b mediated regulation of adult hippocampal neurogenesis: Relevance to mood disorders and antidepressant activity [Review Article]. BioMed Research International. https://doi.org/https://doi.org/10.1155/2014/612798

44. Valente, M. M., Bortolotto, V., Cuccurazzu, B., Ubezio, F., Meneghini, V., Francese, M. T., Canonico, P. L., \& Grilli, M. (2012). A2 $\delta$ ligands act as positive modulators of adult hippocampal neurogenesis and prevent depression-like behavior induced by chronic restraint stress. Molecular Pharmacology, 82(2), 271-280.

https://doi.org/10.1124/mol.112.077636

45. Nasca, C., Xenos, D., Barone, Y., Caruso, A., Scaccianoce, S., Matrisciano, F., Battaglia, G., Mathé, A. A., Pittaluga, A., Lionetto, L., Simmaco, M., \& Nicoletti, F. (2013). Lacetylcarnitine causes rapid antidepressant effects through the epigenetic induction of mGlu2 receptors. Proceedings of the National Academy of Sciences, 110(12), 4804-4809. https://doi.org/10.1073/pnas.1216100110

46. Nasca, C., Bigio, B., Lee, F. S., Young, S. P., Kautz, M. M., Albright, A., Beasley, J., Millington, D. S., Mathé, A. A., Kocsis, J. H., Murrough, J. W., McEwen, B. S., \& Rasgon, N. (2018). Acetyl-l-carnitine deficiency in patients with major depressive disorder. Proceedings of the National Academy of Sciences, 115(34), 8627-8632. https://doi.org/10.1073/pnas.1801609115

47. Veronese, N., Stubbs, B., Solmi, M., Ajnakina, O., Carvalho, A. F., \& Maggi, S. (2018). Acetyl-l-carnitine supplementation and the treatment of depressive symptoms: A systematic review and meta-analysis. Psychosomatic Medicine, 80(2), 154-159. https://doi.org/10.1097/PSY.0000000000000537

48. Chiechio, S., Canonico, P. L., \& Grilli, M. (2018). L-acetylcarnitine: A mechanistically distinctive and potentially rapid-acting antidepressant drug. International Journal of Molecular Sciences, 19(1), 11. https://doi.org/10.3390/ijms19010011

49. Feyissa, A. M., Woolverton, W. L., Miguel-Hidalgo, J. J., Wang, Z., Kyle, P. B., Hasler, G., Stockmeier, C. A., Iyo, A. H., \& Karolewicz, B. (2010). Elevated level of metabotropic glutamate receptor $2 / 3$ in the prefrontal cortex in major depression. Progress in Neuro-Psychopharmacology and Biological Psychiatry, 34(2), 279-283. https://doi.org/10.1016/j.pnpbp.2009.11.018

50. Campo, B., Kalinichev, M., Lambeng, N., Yacoubi, M. E., Royer-Urios, I., Schneider, M., Legrand, C., Parron, D., Girard, F., Bessif, A., Poli, S., Vaugeois, J.-M., Poul, E. L., 
\& Celanire, S. (2011). Characterization of an mglur2/3 negative allosteric modulator in rodent models of depression. Journal of Neurogenetics, 25(4), 152-166. https://doi.org/10.3109/01677063.2011.627485

51. Dwyer, J. M., Lepack, A. E., \& Duman, R. S. (2013). Mglur2/3 blockade produces rapid and long-lasting reversal of anhedonia caused by chronic stress exposure. Journal of Molecular Psychiatry, 1(1), 15. https://doi.org/10.1186/2049-9256-1-15

52. Holmseth, S., Scott, H. A., Real, K., Lehre, K. P., Leergaard, T. B., Bjaalie, J. G., \& Danbolt, N. C. (2009). The concentrations and distributions of three C-terminal variants of the GLT1 (EAAT2; slc1a2) glutamate transporter protein in rat brain tissue suggest differential regulation. Neuroscience, 162(4), 1055-1071. https://doi.org/10.1016/j.neuroscience.2009.03.048

53. Moon, A. L., Haan, N., Wilkinson, L. S., Thomas, K. L., \& Hall, J. (2018). Cacna1c: Association with psychiatric disorders, behavior, and neurogenesis. Schizophrenia Bulletin, 44(5), 958-965. https://doi.org/10.1093/schbul/sby096

54. Zhao, M., Yang, J., Qiu, X., Yang, X., Qiao, Z., Song, X., Wang, L., Zhao, E., Yang, Y., \& Cao, D. (2020). Cacna1c rs1006737, threatening life events, and gene-environment interaction predict major depressive disorder. Frontiers in Psychiatry, 10, 982. https://doi.org/10.3389/fpsyt.2019.00982

55. Heyes, S., Pratt, W. S., Rees, E., Dahimene, S., Ferron, L., Owen, M. J., \& Dolphin, A. C. (2015). Genetic disruption of voltage-gated calcium channels in psychiatric and neurological disorders. Progress in Neurobiology, 134, 36-54. https://doi.org/10.1016/j.pneurobio.2015.09.002

56. Andrade, A., Brennecke, A., Mallat, S., Brown, J., Gomez-Rivadeneira, J., Czepiel, N., \& Londrigan, L. (2019). Genetic associations between voltage-gated calcium channels and psychiatric disorders. International Journal of Molecular Sciences, $20(14), 3537$. https://doi.org/10.3390/ijms20143537

57. Tiger, M., Veldman, E. R., Ekman, C.-J., Halldin, C., Svenningsson, P., \& Lundberg, J. (2020). A randomized placebo-controlled PET study of ketamine's effect on serotonin $1 \mathrm{~B}$ receptor binding in patients with SSRI-resistant depression. Translational Psychiatry, 10(1), 1-8. https://doi.org/10.1038/s41398-020-0844-4

58. Hartmann, A., Fassini, A., Scopinho, A., Correa, F. M., Guimarães, F. S., Lisboa, S. F., \& Resstel, L. B. (2019). Role of the endocannabinoid system in the dorsal hippocampus in the cardiovascular changes and delayed anxiety-like effect induced by acute restraint stress in rats. Journal of Psychopharmacology, 33(5), 606-614. https://doi.org/10.1177/0269881119827799 
59. Gerdeman, G. L., \& Lovinger, D. M. (2003). Emerging roles for endocannabinoids in long-term synaptic plasticity. British Journal of Pharmacology, 140(5), 781-789. https://doi.org/https://doi.org/10.1038/sj.bjp.0705466

60. Williams, N. R., Heifets, B. D., Blasey, C., Sudheimer, K., Pannu, J., Pankow, H., Hawkins, J., Birnbaum, J., Lyons, D. M., Rodriguez, C. I., \& Schatzberg, A. F. (2018). Attenuation of antidepressant effects of ketamine by opioid receptor antagonism. American Journal of Psychiatry, 175(12), 1205-1215. https://doi.org/10.1176/appi.ajp.2018.18020138

61. Yovell, Y., Bar, G., Mashiah, M., Baruch, Y., Briskman, I., Asherov, J., Lotan, A., Rigbi, A., \& Panksepp, J. (2016). Ultra-low-dose buprenorphine as a time-limited treatment for severe suicidal ideation: A randomized controlled trial. American Journal of Psychiatry, 173(5), 491-498. https://doi.org/10.1176/appi.ajp.2015.15040535

62. Ellul, P., Mariotti-Ferrandiz, E., Leboyer, M., \& Klatzmann, D. (2018). Regulatory t cells as supporters of psychoimmune resilience: Toward immunotherapy of major depressive disorder. Frontiers in Neurology, 9, 167. https://doi.org/10.3389/fneur.2018.00167

63. Abdallah, C. G., Jackowski, A., Salas, R., Gupta, S., Sato, J. R., Mao, X., Coplan, J. D., Shungu, D. C., \& Mathew, S. J. (2017). The nucleus accumbens and ketamine treatment in major depressive disorder. Neuropsychopharmacology, 42(8), 1739-1746. https://doi.org/10.1038/npp.2017.49

64. Cao, J.-L., Covington, H. E., Friedman, A. K., Wilkinson, M. B., Walsh, J. J., Cooper, D. C., Nestler, E. J., \& Han, M.-H. (2010). Mesolimbic dopamine neurons in the brain reward circuit mediate susceptibility to social defeat and antidepressant action. Journal of Neuroscience, 30(49), 16453-16458. https://doi.org/10.1523/JNEUROSCI.3177-10.2010

65. Wook Koo, J., Labonté, B., Engmann, O., Calipari, E. S., Juarez, B., Lorsch, Z., Walsh, J. J., Friedman, A. K., Yorgason, J. T., Han, M.-H., \& Nestler, E. J. (2016). Essential role of mesolimbic brain-derived neurotrophic factor in chronic social stress-induced depressive behaviors. Biological Psychiatry, 80(6), 469-478.

https://doi.org/10.1016/j.biopsych.2015.12.009

66. Christoffel, D. J., Golden, S. A., Dumitriu, D., Robison, A. J., Janssen, W. G., Ahn, H. F., Krishnan, V., Reyes, C. M., Han, M.-H., Ables, J. L., Eisch, A. J., Dietz, D. M., Ferguson, D., Neve, R. L., Greengard, P., Kim, Y., Morrison, J. H., \& Russo, S. J. (2011). I b kinase regulates social defeat stress-induced synaptic and behavioral plasticity. Journal of Neuroscience, 31(1), 314-321. https://doi.org/10.1523/JNEUROSCI.4763-10.2011 
67. Dagyte, G., Den Boer, J. A., \& Trentani, A. (2011). The cholinergic system and depression. Behavioural Brain Research, 221(2), 574-582.

https://doi.org/10.1016/j.bbr.2010.02.023

68. Janowsky, D. S., El-Yousef, K. M., \& Davis, J. M. (1974). Acetylcholine and depression*: Psychosomatic Medicine, 36(3), 248-257. https://doi.org/10.1097/00006842-197405000-00008

69. Saricicek, A., Esterlis, I., Maloney, K. H., Mineur, Y. S., Ruf, B. M., Muralidharan, A., Chen, J. I., Cosgrove, K. P., Kerestes, R., Ghose, S., Tamminga, C. A., Pittman, B., Bois, F., Tamagnan, G., Seibyl, J., Picciotto, M. R., Staley, J. K., \& Bhagwagar, Z. (2012). Persistent $\beta_{2}$ *-nicotinic acetylcholinergic receptor dysfunction in major depressive disorder. American Journal of Psychiatry, 169(8), 851-859. https://doi.org/10.1176/appi.ajp.2012.11101546

70. Higley, M. J., \& Picciotto, M. R. (2014). Neuromodulation by acetylcholine: Examples from schizophrenia and depression. Current Opinion in Neurobiology, 29, 88-95. https://doi.org/10.1016/j.conb.2014.06.004

71. Mineur, Y. S., Obayemi, A., Wigestrand, M. B., Fote, G. M., Calarco, C. A., Li, A. M., \& Picciotto, M. R. (2013). Cholinergic signaling in the hippocampus regulates social stress resilience and anxiety- and depression-like behavior. Proceedings of the National Academy of Sciences, 110(9), 3573-3578. https://doi.org/10.1073/pnas.1219731110

72. Cheng, Q., \& Yakel, J. L. (2015). The effect of $\alpha 7$ nicotinic receptor activation on glutamatergic transmission in the hippocampus. Biochemical Pharmacology, 97(4), 439444. https://doi.org/10.1016/j.bcp.2015.07.015

73. McClernon, F. J., Hiott, F. B., Westman, E. C., Rose, J. E., \& Levin, E. D. (2006). Transdermal nicotine attenuates depression symptoms in nonsmokers: A double-blind, placebo-controlled trial. Psychopharmacology, 189(1), 125-133. https://doi.org/10.1007/s00213-006-0516-y

74. Gandelman, J. A., Kang, H., Antal, A., Albert, K., Boyd, B. D., Conley, A. C., Newhouse, P., \& Taylor, W. D. (2018). Transdermal nicotine for the treatment of mood and cognitive symptoms in nonsmokers with late-life depression. The Journal of Clinical Psychiatry, 79(5). https://doi.org/10.4088/JCP.18m12137

75. Carroll, F. I., Blough, B. E., Mascarella, S. W., Navarro, H. A., Lukas, R. J., \& Damaj, M. I. (2014). Bupropion and bupropion analogs as treatments for cns disorders. In Advances in Pharmacology (Vol. 69, pp. 177-216). Elsevier. https://doi.org/10.1016/B978-0-12-420118-7.00005-6 
76. Mineur, Y. S., Fote, G. M., Blakeman, S., Cahuzac, E. L. M., Newbold, S. A., \& Picciotto, M. R. (2016). Multiple nicotinic acetylcholine receptor subtypes in the mouse amygdala regulate affective behaviors and response to social stress. Neuropsychopharmacology, 41(6), 1579-1587. https://doi.org/10.1038/npp.2015.316

77. Han, J., Wang, D., Liu, S., \& Zhao, M. (2016). Cytisine, a partial agonist of $\alpha 4 \beta 2$ nicotinic acetylcholine receptors, reduced unpredictable chronic mild stress-induced depression-like behaviors. Biomolecules \& Therapeutics, 24(3), 291-297. https://doi.org/10.4062/biomolther.2015.113

78. Zhang, J., Yao, W., Ren, Q., Yang, C., Dong, C., Ma, M., Wu, J., \& Hashimoto, K. (2016). Depression-like phenotype by deletion of $\alpha 7$ nicotinic acetylcholine receptor: Role of BDNF-TrkB in nucleus accumbens. Scientific Reports, 6(1), 36705. https://doi.org/10.1038/srep36705

79. Pohanka, M. (2012). Alpha7 nicotinic acetylcholine receptor is a target in pharmacology and toxicology. International Journal of Molecular Sciences, 13(2), 2219-2238. https://doi.org/10.3390/ijms13022219

80. Niehaus, J. L., Murali, M., \& Kauer, J. A. (2010). Drugs of abuse and stress impair LTP at inhibitory synapses in the ventral tegmental area: Drugs and stress block LTPGABA. European Journal of Neuroscience, 32(1), 108-117. https://doi.org/10.1111/j.1460-9568.2010.07256.x

81. Morel, C., Fernandez, S. P., Pantouli, F., Meye, F. J., Marti, F., Tolu, S., Parnaudeau, S., Marie, H., Tronche, F., Maskos, U., Moretti, M., Gotti, C., Han, M.-H., Bailey, A., Mameli, M., Barik, J., \& Faure, P. (2018). Nicotinic receptors mediate stress-nicotine detrimental interplay via dopamine cells' activity. Molecular Psychiatry, 23(7), 15971605. https://doi.org/10.1038/mp.2017.145

82. Esterlis, I., Cosgrove, K. P., Batis, J. C., Bois, F., Kloczynski, T. A., Stiklus, S. M., Perry, E., Tamagnan, G. D., Seibyl, J. P., Makuch, R., Krishnan-Sarin, S., O’Malley, S., \& Staley, J. K. (2009). GABA A -benzodiazepine receptor availability in smokers and nonsmokers: Relationship to subsyndromal anxiety and depression. Synapse, 63(12), 1089-1099. https://doi.org/10.1002/syn.20688

83. Darrow, S. M., Verhoeven, J. E., Révész, D., Lindqvist, D., Penninx, B. W. J. H., Delucchi, K. L., Wolkowitz, O. M., \& Mathews, C. A. (2016). The association between psychiatric disorders and telomere length: A meta-analysis involving 14,827 persons. Psychosomatic Medicine, 78(7), 776-787. https://doi.org/10.1097/PSY.0000000000000356 
84. Hough, C. M., Bersani, F. S., Mellon, S. H., Epel, E. S., Reus, V. I., Lindqvist, D., Lin, J., Mahan, L., Rosser, R., Burke, H., Coetzee, J., Nelson, J. C., Blackburn, E. H., \& Wolkowitz, O. M. (2016). Leukocyte telomere length predicts ssri response in major depressive disorder: A preliminary report. Molecular Neuropsychiatry, 2(2), 88-96. https://doi.org/10.1159/000446500

85. Wolkowitz, O. M., Mellon, S. H., Epel, E. S., Lin, J., Reus, V. I., Rosser, R., Burke, H., Compagnone, M., Nelson, J. C., Dhabhar, F. S., \& Blackburn, E. H. (2012). Resting leukocyte telomerase activity is elevated in major depression and predicts treatment response. Molecular Psychiatry, 17(2), 164-172. https://doi.org/10.1038/mp.2010.133

86. Pan, W., \& Kastin, A. (2008). Urocortin and the brain. Progress in Neurobiology, 84(2), 148-156. https://doi.org/10.1016/j.pneurobio.2007.10.008

87. Agudelo, L. Z., Ferreira, D. M. S., Dadvar, S., Cervenka, I., Ketscher, L., Izadi, M., Zhengye, L., Furrer, R., Handschin, C., Venckunas, T., Brazaitis, M., Kamandulis, S., Lanner, J. T., \& Ruas, J. L. (2019). Skeletal muscle PGC-1 $\alpha 1$ reroutes kynurenine metabolism to increase energy efficiency and fatigue-resistance. Nature Communications, 10(1), 2767. https://doi.org/10.1038/s41467-019-10712-0

88. Rius-Pérez, S., Torres-Cuevas, I., Millán, I., Ortega, Á. L., \& Pérez, S. (2020). Pgc-1 $\alpha$, inflammation, and oxidative stress: An integrative view in metabolism. Oxidative Medicine and Cellular Longevity, 2020, 1-20. https://doi.org/10.1155/2020/1452696

89. Jang, S.-W., Liu, X., Chan, C.-B., Weinshenker, D., Hall, R. A., Xiao, G., \& Ye, K. (2009). Amitriptyline is a trka and trkb receptor agonist that promotes trka/trkb heterodimerization and has potent neurotrophic activity. Chemistry \& Biology, 16(6), 644-656. https://doi.org/10.1016/j.chembiol.2009.05.010

90. Puang, S. J., Elanggovan, B., Ching, T., \& Sng, J. C. G. (2020). MEF2C and HDAC5 regulate Egrl and Arc genes to increase dendritic spine density and complexity in early enriched environment. Neuronal Signaling, 4(3), NS20190147. https://doi.org/10.1042/NS20190147

91. Golden, S. A., Christoffel, D. J., Heshmati, M., Hodes, G. E., Magida, J., Davis, K., Cahill, M. E., Dias, C., Ribeiro, E., Ables, J. L., Kennedy, P. J., Robison, A. J., GonzalezMaeso, J., Neve, R. L., Turecki, G., Ghose, S., Tamminga, C. A., \& Russo, S. J. (2013). Epigenetic regulation of RAC1 induces synaptic remodeling in stress disorders and depression. Nature Medicine, 19(3), 337-344. https://doi.org/10.1038/nm.3090

92. Huang, T., Zhou, F., Wang-Johanning, F., Nan, K., \& Wei, Y. (2016). Depression accelerates the development of gastric cancer through reactive oxygen species-activated 
ABL1 (Review). Oncology Reports, 36(5), 2435-2443.

https://doi.org/10.3892/or.2016.5127

93. Dias, C., Feng, J., Sun, H., Shao, N. yi, Mazei-Robison, M. S., Damez-Werno, D., Scobie, K., Bagot, R., LaBonté, B., Ribeiro, E., Liu, X., Kennedy, P., Vialou, V., Ferguson, D., Peña, C., Calipari, E. S., Koo, J. W., Mouzon, E., Ghose, S., ... Nestler, E. J. (2014). B-catenin mediates stress resilience through dicer1/microrna regulation. Nature, 516(7529), 51-55. https://doi.org/10.1038/nature13976

94. Han, F., Konkalmatt, P., Mokashi, C., Kumar, M., Zhang, Y., Ko, A., Farino, Z. J., Asico, L. D., Xu, G., Gildea, J., Zheng, X., Felder, R. A., Lee, R. E. C., Jose, P. A., Freyberg, Z., \& Armando, I. (2019). Dopamine D2 receptor modulates Wnt expression and control of cell proliferation. Scientific Reports, 9(1), 16861. https://doi.org/10.1038/s41598-019$\underline{52528-4}$

95. Ortiz-Matamoros, A., Salcedo-Tello, P., Avila-Muñoz, E., Zepeda, A., \& Arias, C. (2013). Role of wnt signaling in the control of adult hippocampal functioning in health and disease: Therapeutic implications. Current Neuropharmacology, 11(5), 465-476. https://doi.org/10.2174/1570159X11311050001

96. Abe, K., \& Takeichi, M. (2007). Nmda-receptor activation induces calpain-mediated $\beta$ catenin cleavages for triggering gene expression. Neuron, 53(3), 387-397. https://doi.org/10.1016/j.neuron.2007.01.016

97. Goretsky, T., Bradford, E. M., Ye, Q., Lamping, O. F., Vanagunas, T., Moyer, M. P., Keller, P. C., Sinh, P., Llovet, J. M., Gao, T., She, Q.-B., Li, L., \& Barrett, T. A. (2018). Beta-catenin cleavage enhances transcriptional activation. Scientific Reports, 8(1), 671. https://doi.org/10.1038/s41598-017-18421-8

98. Wilkinson, M. B., Dias, C., Magida, J., Mazei-Robison, M., Lobo, M., Kennedy, P., Dietz, D., Covington, H., Russo, S., Neve, R., Ghose, S., Tamminga, C., \& Nestler, E. J. (2011). A novel role of the WNT-dishevelled-GSK3 $\beta$ signaling cascade in the mouse nucleus accumbens in a social defeat model of depression. The Journal of Neuroscience: The Official Journal of the Society for Neuroscience, 31(25), 9084-9092. https://doi.org/10.1523/JNEUROSCI.0039-11.2011

99. Aceto, G., Colussi, C., Leone, L., Fusco, S., Rinaudo, M., Scala, F., Green, T. A., Laezza, F., D’Ascenzo, M., \& Grassi, C. (2020). Chronic mild stress alters synaptic plasticity in the nucleus accumbens through GSK3 $\beta$-dependent modulation of Kv4.2 channels. Proceedings of the National Academy of Sciences, 117(14), 8143-8153. https://doi.org/10.1073/pnas.1917423117 
100.Dhir, A., \& Kulkarni, S. K. (2011). Nitric oxide and major depression. Nitric Oxide, 24(3), 125-131. https://doi.org/10.1016/j.niox.2011.02.002

101.Covington, H. E., Maze, I., LaPlant, Q. C., Vialou, V. F., Ohnishi, Y. N., Berton, O., Fass, D. M., Renthal, W., Rush, A. J., Wu, E. Y., Ghose, S., Krishnan, V., Russo, S. J., Tamminga, C., Haggarty, S. J., \& Nestler, E. J. (2009). Antidepressant actions of histone deacetylase inhibitors. Journal of Neuroscience, 29(37), 11451-11460. https://doi.org/10.1523/JNEUROSCI.1758-09.2009

102.Jacobs, J. M., Traeger, L., Eusebio, J., Simon, N. M., Sequist, L. V., Greer, J. A., Temel, J. S., \& Pirl, W. F. (2017). Depression, inflammation, and epidermal growth factor receptor (Egfr) status in metastatic non-small cell lung cancer: A pilot study. Journal of Psychosomatic Research, 99, 28-33. https://doi.org/10.1016/j.jpsychores.2017.05.009

103.Hu, Y., Hong, X.-Y., Yang, X.-F., Ma, R.-H., Wang, X., Zhang, J.-F., Feng, Q., Li, X.G., Sun, D.-S., Li, X., Wan, H.-L., Li, T., Wang, Q., Ke, D., Wang, J.-Z., \& Liu, G.-P. (2019). Inflammation-dependent ISG15 upregulation mediates MIA-induced dendrite damages and depression by disrupting NEDD4/Rap2A signaling. Biochimica et Biophysica Acta (BBA) - Molecular Basis of Disease, 1865(6), 1477-1489. https://doi.org/10.1016/j.bbadis.2019.02.020

104.Wang, B., Lian, Y.-J., Su, W.-J., Peng, W., Dong, X., Liu, L.-L., Gong, H., Zhang, T., Jiang, C.-L., \& Wang, Y.-X. (2018). HMGB1 mediates depressive behavior induced by chronic stress through activating the kynurenine pathway. Brain, Behavior, and Immunity, 72, 51-60. https://doi.org/10.1016/j.bbi.2017.11.017

105.Sustained antidepressant effect of PEA replacement. (1996). The Journal of Neuropsychiatry and Clinical Neurosciences, 8(2), 168-171. https://doi.org/10.1176/jnp.8.2.168

106.De Gregorio, D., Manchia, M., Carpiniello, B., Valtorta, F., Nobile, M., Gobbi, G., \& Comai, S. (2019). Role of palmitoylethanolamide (Pea) in depression: Translational evidence. Journal of Affective Disorders, 255, 195-200. https://doi.org/10.1016/j.jad.2018.10.117

107.Nisbett, K. E., \& Pinna, G. (2018). Emerging therapeutic role of ppar- $\alpha$ in cognition and emotions. Frontiers in Pharmacology, 9, 998. https://doi.org/10.3389/fphar.2018.00998

108.Garay, R., Zarate, C. A., Cavero, I., Kim, Y.-K., Charpeaud, T., \& Skolnick, P. (2018). The development of glutamate-based antidepressants is taking longer than expected. Drug Discovery Today, 23(10), 1689-1692. https://doi.org/10.1016/j.drudis.2018.02.006 
109.Hawrylycz, M. J., Lein, E. S., Guillozet-Bongaarts, A. L., Shen, E. H., Ng, L., Miller, J. A., van de Lagemaat, L. N., Smith, K. A., Ebbert, A., Riley, Z. L., Abajian, C., Beckmann, C. F., Bernard, A., Bertagnolli, D., Boe, A. F., Cartagena, P. M., Chakravarty, M. M., Chapin, M., Chong, J., ... Jones, A. R. (2012). An anatomically comprehensive atlas of the adult human brain transcriptome. Nature, 489(7416), 391-399. https://doi.org/10.1038/nature11405

110.Huang, D. W., Sherman, B. T., \& Lempicki, R. A. (2009). Systematic and integrative analysis of large gene lists using DAVID bioinformatics resources. Nature Protocols, 4(1), 44-57. https://doi.org/10.1038/nprot.2008.211

111.Huang, D. W., Sherman, B. T., \& Lempicki, R. A. (2009). Bioinformatics enrichment tools: Paths toward the comprehensive functional analysis of large gene lists. Nucleic Acids Research, 37(1), 1-13. https://doi.org/10.1093/nar/gkn923

112. Kanehisa, M. (2000). Kegg: Kyoto encyclopedia of genes and genomes. Nucleic Acids Research, 28(1), 27-30. https://doi.org/10.1093/nar/28.1.27

113.Szklarczyk, D., Gable, A. L., Lyon, D., Junge, A., Wyder, S., Huerta-Cepas, J., Simonovic, M., Doncheva, N. T., Morris, J. H., Bork, P., Jensen, L. J., \& Mering, C. von. (2019). STRING v11: Protein-protein association networks with increased coverage, supporting functional discovery in genome-wide experimental datasets. Nucleic Acids Research, 47(D1), D607-D613. https://doi.org/10.1093/nar/gky1131

114.Shannon, P. (2003). Cytoscape: A software environment for integrated models of biomolecular interaction networks. Genome Research, 13(11), 2498-2504. https://doi.org/10.1101/gr.1239303

115.Bader, G.D., Hogue, C.W. An automated method for finding molecular complexes in large protein interaction networks. BMC Bioinformatics 4, 2 (2003). https://doi.org/10.1186/1471-2105-4-2

116.Morris, J. H., Apeltsin, L., Newman, A. M., Baumbach, J., Wittkop, T., Su, G., Bader, G. D., \& Ferrin, T. E. (2011). Clustermaker: A multi-algorithm clustering plugin for cytoscape. BMC Bioinformatics, 12(1), 436. https://doi.org/10.1186/1471-2105-12-436

117.Merico, D., Isserlin, R., Stueker, O., Emili, A., \& Bader, G. D. (2010). Enrichment map: A network-based method for gene-set enrichment visualization and interpretation. PLoS ONE, 5(11), e13984. https://doi.org/10.1371/journal.pone.0013984

118.Zhou, G., Soufan, O., Ewald, J., Hancock, R. E. W., Basu, N., \& Xia, J. (2019). NetworkAnalyst 3.0: A visual analytics platform for comprehensive gene expression profiling and meta-analysis. Nucleic Acids Research,47(W1), W234-W241. https://doi.org/10.1093/nar/gkz240 
119. Conway, J. R., Lex, A., \& Gehlenborg, N. (2017). UpSetR: An R package for the visualization of intersecting sets and their properties. Bioinformatics, 33(18), 2938-2940. https://doi.org/10.1093/bioinformatics/btx364

120.Covington, H. E., \& Miczek, K. A. (2001). Repeated social-defeat stress, cocaine or morphine. Effects on behavioral sensitization and intravenous cocaine self-administration "binges." Psychopharmacology, 158(4), 388-398.

https://doi.org/10.1007/s002130100858

121.Covington, H. E., Tropea, T. F., Rajadhyaksha, A. M., Kosofsky, B. E., \& Miczek, K. A. (2008). NMDA receptors in the rat VTA: A critical site for social stress to intensify cocaine taking. Psychopharmacology, 197(2), 203-216. https://doi.org/10.1007/s00213007-1024-4 


\section{Conflict of Interest}

The author declares no conflict of interest. 